\title{
Strong Electronic Coupling between Ultrafine Iridium- Ruthenium Nanoclusters and Conductive, Acid-Stable Tellurium Nanoparticle Support for Efficient and Durable Oxygen Evolution in Acidic and Neutral Media
}

Junyuan Xu, ${ }^{\dagger, \#}$ Zan Lian, ${ }^{\dagger, \#}$ Bin Wei, ${ }^{\dagger, \#}$ Yue Li, ${ }^{\dagger, \|}$ Oleksandr Bondarchuk, ${ }^{\dagger}$ Nan Zhang, ${ }^{\dagger}$ Zhipeng Yu, ${ }^{\dagger, \perp}$ Ana Araujo, ${ }^{\dagger}$ Isilda Amorim, ${ }^{\dagger, l}$ Zhongchang Wang, ${ }^{+,}{ }^{*}$ Bo Li, ${ }^{\ddagger},{ }^{*}$ and Lifeng $\mathrm{Liu}^{\dagger, *}$

†International Iberian Nanotechnology Laboratory (INL), Avenida Mestre Jose Veiga, 4715-330 Braga, Portugal

¥Shenyang National Laboratory for Materials Science, Institute of Metal Research, Chinese Academy of Sciences, 72 Wenhua Road, 110016 Shenyang, China

"Center of Chemistry, Chemistry Department, University of Minho, Gualtar Campus, Braga, 4710-057, Portugal

${ }^{\perp}$ Laboratory of Catalysis and Materials (LSRE-LCM), Faculdade de Engenharia, Universidade do Porto, Rua Dr. Roberto Frias, 4200-465 Porto, Portugal

Corresponding Author

*E-mail: zhongchang.wang@inl.int (Z. C. Wang)

boli@imr.ac.cn (B. Li)

lifeng.liu@inl.int (L. F. Liu) 


\section{Experimental Procedures}

\section{Synthesis of IrRu@Te}

The IrRu@Te catalysts were synthesized by a previously reported method with some modification. ${ }^{\mathrm{s1}}$ Typically, $0.875 \mathrm{~g}$ of PVP-40ooo was dissolved in $26.25 \mathrm{~mL}$ of deionized water under vigorous magnetic stirring to form a homogeneous solution at $25^{\circ} \mathrm{C}$. Then, $0.065 \mathrm{~g}$ of $\mathrm{Na}_{2} \mathrm{TeO}_{3}, 0.131 \mathrm{~g}$ of $\mathrm{IrCl}_{3}$. $x \mathrm{H}_{2} \mathrm{O}$ and $0.091 \mathrm{~g}$ of $\mathrm{RuCl}_{3} \cdot x \mathrm{H}_{2} \mathrm{O}$ were added into the above solution and dissolved, followed by the addition of $5.86 \mathrm{~mL}$ of hydrazine hydrate and $2.89 \mathrm{~mL}$ of ammonia solution. After stirring for $10 \mathrm{~min}$, the mixed solution was transferred into a Teflon-lined stainless steel autoclave and maintained at 180 ${ }^{\circ} \mathrm{C}$ for $18 \mathrm{~h}$. Subsequently, the reactor was naturally cooled down to $25{ }^{\circ} \mathrm{C}$. The obtained black precipitates were centrifuged, washed two times with deionized water and acetone sequentially, and dried under vacuum at $60^{\circ} \mathrm{C}$ for further use.

\section{Synthesis of unsupported IrRu}

The unsupported IrRu catalysts were synthesized using the same procedure as described above without the addition of $\mathrm{Na}_{2} \mathrm{TeO}_{3}$.

\section{Synthesis of pristine Te}

The pristine Te control was synthesized using the same procedure as described above except that $\mathrm{IrCl}_{3} \cdot x \mathrm{H}_{2} \mathrm{O}$ and $\mathrm{RuCl}_{3} \cdot x \mathrm{H}_{2} \mathrm{O}$ were not added.

\section{Materials characterization}

Powder XRD examinations were conducted on a X'Pert PRO diffractometer (PANalytical) working at $45 \mathrm{kV}$ and $40 \mathrm{~mA}$ with $\mathrm{Cu} K_{\alpha}$ radiation $(\lambda=1.541874 \AA)$ and a PIXcel detector. Data were collected with the Bragg-Brentano configuration in the $2 \theta$ range of $20-80^{\circ}$ at a scan speed of $0.01^{\circ} \mathrm{s}^{-1}$. XPS characterization was performed on an ESCALAB 250Xi instrument with Al $K_{\alpha}$ X-ray source (1486.6 eV). The composition of IrRu@Te and IrRu and the metal loss during OER stability tests were determined by ICP-OES (ICPE-9ooo spectrometer, Shimadzu). Nitrogen adsorption/desorption porosimetry was performed using a Quantachrome Autosorb IQ 2 system at 77 K. TEM, HRTEM, and STEM investigations were carried out on a probe-corrected transmission electron microscope operating at $200 \mathrm{kV}$ (FEI Themis $60-300$ ). The electrical conductivity of the Te support before and after electrochemical oxidization under OER conditions was measured. Specifically, $200 \mathrm{mg}$ of freshly prepared Te powders was pressed into a circular disk of $0.55 \mathrm{~mm}$ in thickness (determined by vernier caliper) without any additives under a pressure of 1 ton, using a press machine (Specac). The asobtained disk was electrochemically oxidized in $0.5 \mathrm{M} \mathrm{H}_{2} \mathrm{SO}_{4}$ under OER conditions at $10 \mathrm{~mA} \mathrm{~cm}^{-2}$ for $30 \mathrm{~min}$. The average sheet resistance of the pristine Te and electrochemically oxidized Te was measured to be 0.03 and $7.35 \Omega / \square$, using a four-probe station (CMT-SR2oooN, AITCO). Therefore, the electrical conductivities of the pristine Te and oxidized support were computed to be 606 and 2.5 $\mathrm{S} \mathrm{cm}^{-1}$, respectively.

\section{DFT calculations}

The spin-polarized calculations were performed using periodic density functional theory as implemented in Vienna $a b$ initio simulation package (VASP). ${ }^{\text {s2-s4 }} \mathrm{A}$ plane-wave basis set was adopted for valence electrons with an energy cutoff of $450 \mathrm{eV}$ and the ionic cores were described with the projector augmented-wave (PAW) method. ${ }^{55,56}$ The $\mathrm{RPBE}^{\mathrm{s} 7}$ functional was used as the exchange-correlation functional approximation with the 
DFT-D3 correction method reported by Grimme et al. ${ }^{\mathrm{s} 8}$ The bulk of IrRu with space group of PM-3M (221) was built by replacing two Ir atoms with $\mathrm{Ru}$ atoms in the bulk of Ir, and the bulk of $\mathrm{IrRuO}_{2}$ was built by replacing a $\mathrm{Ru}$ atom with an Ir atom in the bulk of $\mathrm{RuO}_{2}$. A five layer slab unit cell was used to model the IrRu (111) surface, and IrRu@Te was represented by replacing the metal atoms at the central layer of IrRu (111). A stoichiometric nine layer slab with a p $(2 \times 1)$ supercell, where the six layers at bottom are fixed, was used to model the $\mathrm{IrRuO}_{2}$ (110) surface, and oxidized IrRu@Te was represented by replacing the metal atoms at the central layer of $\mathrm{IrRuO}_{2}$ (110). The thickness of vacuum region of each model is $12 \AA .5 \times 5 \times 1$ and $3 \times 3 \times 1$ Monk horst-Pack k-point grids were employed to sample the Brillion zone for structure optimized calculations of alloy surface and metal oxide surface, respectively. A finer grid of $9 \times 9 \times 1$ was utilized for DOS calculations. The total energy was converged with an accuracy of $1 \times 10^{-6} \mathrm{eV} /$ atom to obtain accurate forces, and force tolerance of $0.03 \mathrm{eV} / \AA ̊$ was adopted in structure optimization.

The following four elementary steps are considered for OER in this work. ${ }^{\text {s9 }}$

$$
\begin{aligned}
& 2 \mathrm{H}_{2} \mathrm{O}+{ }^{*} \rightarrow \mathrm{OH}^{*}+\mathrm{H}_{2} \mathrm{O}+\mathrm{e}^{-}+\mathrm{H}^{+} \\
& \mathrm{OH}^{*}+\mathrm{H}_{2} \mathrm{O} \rightarrow \mathrm{O}^{*}+\mathrm{H}_{2} \mathrm{O}+\mathrm{e}^{-}+\mathrm{H}^{+} \\
& \mathrm{O}^{*}+\mathrm{H}_{2} \mathrm{O} \rightarrow \mathrm{OOH}^{*}+\mathrm{e}^{-}+\mathrm{H}^{+} \\
& \mathrm{OOH}^{*} \rightarrow \mathrm{O}_{2}+\mathrm{e}^{-}+\mathrm{H}^{+}
\end{aligned}
$$

The Gibbs free energy change of the four steps at potential U ( $v s$ RHE) was calculated by:

$$
\begin{aligned}
& \Delta \mathrm{G}_{1}=\Delta \mathrm{G}_{\mathrm{OH}}-\mathrm{eU} \\
& \Delta \mathrm{G}_{2}=\Delta \mathrm{G}_{\mathrm{O}}-\Delta \mathrm{G}_{\mathrm{OH}}-\mathrm{eU} \\
& \Delta \mathrm{G}_{3}=\Delta \mathrm{G}_{\mathrm{OOH}}-\Delta \mathrm{G}_{\mathrm{O}}-\mathrm{eU} \\
& \Delta \mathrm{G}_{4}=\Delta \mathrm{G}_{\mathrm{O}_{2}}-\Delta \mathrm{G}_{\mathrm{OH}}-\mathrm{eU}
\end{aligned}
$$

where the Gibbs free energy of adsorbate is referenced to $\mathrm{H}_{2} \mathrm{O}$ and $\mathrm{H}_{2}$ at standard conditions and o V vs RHE:

$$
\begin{aligned}
& \Delta \mathrm{G}_{\mathrm{OH}}=\mathrm{G}_{\mathrm{OH}}{ }^{*}-\mathrm{E}_{\text {slab }}-\mathrm{G}_{\mathrm{H}_{2} \mathrm{O}}+0.5 \mathrm{G}_{\mathrm{H}_{2}} \\
& \Delta \mathrm{G}_{\mathrm{O}}=\mathrm{GO}^{*}-\mathrm{E}_{\text {slab }}-\mathrm{G}_{\mathrm{H}_{2} \mathrm{O}}+\mathrm{G}_{\mathrm{H}_{2}} \\
& \Delta \mathrm{G}_{\mathrm{OOH}}=\mathrm{GOOH}^{*}-\mathrm{E}_{\text {slab }}-2 \mathrm{G}_{\mathrm{H}_{2} \mathrm{O}}+1.5 \mathrm{G}_{\mathrm{H}_{2}} \\
& \Delta \mathrm{G}_{\mathrm{O}_{2}}=4.92 \mathrm{eV}
\end{aligned}
$$

where $\mathrm{G}_{\mathrm{i}}=\mathrm{E}_{\mathrm{i}}+\mathrm{ZPE}_{\mathrm{i}}+\mathrm{TS}_{\mathrm{i}}\left(\mathrm{i}=\mathrm{OH}^{*}, \mathrm{OOH}^{*}, \mathrm{H}_{2} \mathrm{O}\right.$, and $\left.\mathrm{H}_{2}\right)$, $\mathrm{E}_{\mathrm{i}}$ is the energy obtained from DFT calculations, and $\mathrm{ZPE}_{\mathrm{i}}$ and $\mathrm{S}_{\mathrm{i}}$ were computed by DFT calculations of frequencies at $298 \mathrm{~K}$, while the entropy of $\mathrm{H}_{2} \mathrm{O}$ and $\mathrm{H}_{2}$ were obtained from experimental database at 0.035 bar, $298 \mathrm{~K}$ and 1 bar, 298 K, respectively. ${ }^{\text {sio }}$

\section{Electrode preparation and electrocatalytic tests}

The catalyst ink was prepared by ultrasonically dispersing $5 \mathrm{mg}$ of catalysts into $0.5 \mathrm{~mL}$ of ethanol containing $50 \mu \mathrm{L}$ of Nafion ${ }^{\circledR}$ solution. To prepare an electrode for catalytic tests, 9, 18, 36 or $54 \mu \mathrm{L}$ of catalyst ink was loaded on a fine-polished glassy carbon (GC) electrode with an exposed area of $0.60 \mathrm{~cm}^{2}$, leading to a loading density of ca. $0.15,0.30$, 0.60 or $0.90 \mathrm{mg} \mathrm{cm}^{-2}$, respectively. The electrode was then dried at room temperature (ca. $25^{\circ} \mathrm{C}$ ) naturally in air. All electrocatalytic tests were carried out in a three-electrode configuration at room temperature using a Biologic VMP-3 potentiostat/galvanostat. The catalyst-loaded GC, a Pt wire and a saturated calomel electrode (SCE) were utilized as working, counter, and reference electrodes, respectively. The SCE reference electrode was calibrated prior to each measurement in $\mathrm{Ar} / \mathrm{H}_{2}$-saturated $0.5 \mathrm{M} \mathrm{H}_{2} \mathrm{SO}_{4}$ 
solution using a clean Pt wire as the working electrode. 0.5 $\mathrm{M} \mathrm{H}_{2} \mathrm{SO}_{4}$, $0.05 \mathrm{M} \mathrm{H}_{2} \mathrm{SO}_{4}$, or PBS was used as the electrolyte. Unless otherwise stated, all potentials are reported versus RHE by converting the measured potentials according to the following equation:

$\mathrm{E}_{\mathrm{RHE}}=\mathrm{E}_{\mathrm{SCE}}+0.059 \times \mathrm{pH}+0.241$

The apparent OER activity was characterized using CV at a scan rate of $5 \mathrm{mV} \mathrm{s}^{-1}$, and an $i R$-correction (85\%) was made to compensate the voltage drop between the reference and working electrodes, which was measured by a single-point high-frequency impedance test. The reduction branch of the CV curves was used for performance comparison of all the catalysts.

The ECSAs were calculated from the electrochemical double-layer capacitance of the catalytic surface. The double layer capacitance $\left(C_{\mathrm{dl}}\right)$ of catalysts was estimated by performing $\mathrm{CV}$ in the potential range of 0.96 to 1.16 V vs RHE (non-Faradaic potential range) at different scan rates $(v)$ of 20, 40, 6o, 80 and $100 \mathrm{mV} \mathrm{s}^{-1}$, followed by extracting the slope from the resulting $\left|j_{a}-j_{\mathrm{c}}\right| / 2 v s v$ plots $\left(j_{\mathrm{a}}\right.$ and $j_{\mathrm{c}}$ represent the anodic and cathodic currents at $1.06 \mathrm{~V}$ vs RHE). The ECSA can be computed by dividing the measured $C_{\mathrm{dl}}$ by the capacitance of a model catalyst over a unit surface area (0.06 $\mathrm{mF} \mathrm{cm}_{\mathrm{geo}^{-2}}$ for $\mathrm{Ir}$, Ru and their oxides). ${ }^{\text {s11 }}$

$\mathrm{ECSA}=C_{\mathrm{dl}} / 0.06 \mathrm{mF} \mathrm{cm}^{-2}$

The stability was assessed using $\mathrm{CP}$ at a constant current density of $10 \mathrm{~mA} \mathrm{~cm}{ }^{-2}$.

The overall water splitting tests were performed in a two-compartment Teflon cell separated by a piece of Nafion ${ }^{\circledR} 115$ (FuelCellStore) membrane, using 0.5 $\mathrm{M} \mathrm{H}_{2} \mathrm{SO}_{4}$, o.05 $\mathrm{M} \mathrm{H}_{2} \mathrm{SO}_{4}$, or PBS as the electrolyte. IrRu@Te and $\mathrm{Pt} / \mathrm{C}$ (2o wt\%, FuelCellStore) were cast on GC electrodes and used as anode and cathode catalysts, respectively. For comparison, commercially available $\mathrm{Ir} / \mathrm{C}$ ( $20 \mathrm{wt} \%$, FuelCellStore) or $\mathrm{RuO}_{2}$ was also utilized as anode catalysts. The anode and cathode catalyst loading was $0.6 \mathrm{mg} \mathrm{cm}^{-2}$. CV curves were recorded at a scan rate of $5 \mathrm{mV} \mathrm{s}^{-1}$ with iR-correction (85\%). 


\section{Supporting figures}
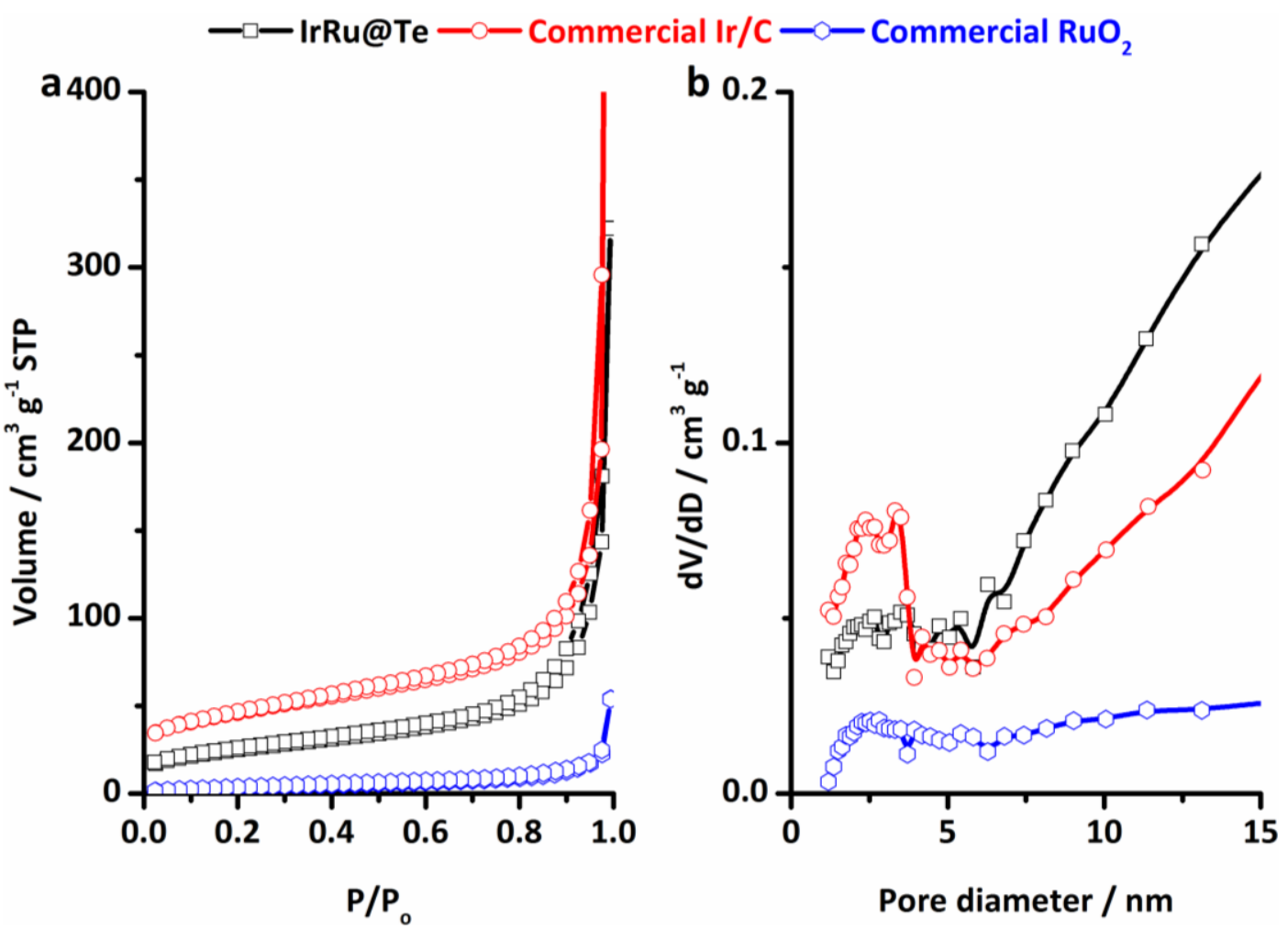

Figure S1. (a) $\mathrm{N}_{2}$ adsorption/desorption isotherms and (b) the corresponding pore size distribution plots of IrRu@Te, commercial Ir/C and commercial $\mathrm{RuO}_{2}$ catalysts. 
a

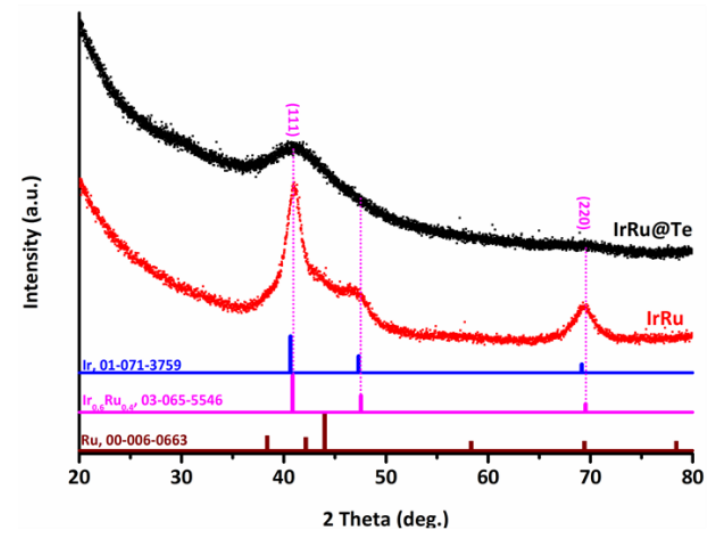

b

\begin{tabular}{|c|c|}
\hline$\underline{R u_{0,01}} \mathrm{Ir}_{0,99}$ & $\begin{array}{c}\text { Cubic } \\
\mid\end{array}$ \\
\hline $\mathrm{Ru}_{0,3} \mathbf{I}_{0.7}$ & $\perp$ \\
\hline$\underline{R \mathbf{u}_{0.37}} \mathrm{Ir}_{0.63}$ & $\perp$ \\
\hline$\underline{\mid \mathrm{Ir}_{0.62} R \mathrm{u}_{0.38}}$ & $\perp$ \\
\hline $\mathrm{Ru}_{0.4} \mathrm{Ir}_{0.6}$ & $\perp$ \\
\hline $\mathrm{Ir}_{0.6} \mathrm{Ru}_{0.4}$ & $\perp$ \\
\hline $\mathrm{Ru}_{0.5} \mathbf{I r}_{0.5}$ & Hexagonal \\
\hline$\underline{I_{0.44} R u_{0.56}}$ & \\
\hline$\underline{\mathbf{R u}} \mathbf{u}_{0.6} \mathbf{I r}_{0.4}$ & \\
\hline $\mathrm{Ru}_{0.67} \mathrm{Ir}_{0.33}$ & \\
\hline 20 & 60 \\
\hline
\end{tabular}

Figure S2. (a) XRD patterns of unsupported IrRu and IrRu@Te. The standard powder diffraction patterns of cubic Ir (ICDD No. o1-071-3759), cubic $\mathrm{Ir}_{\mathrm{o} .6} \mathrm{Ru}_{0.4}$ (ICDD No. 03-065-5546) and hexagonal Ru (ICDD No. oo-oo6-0663) are given for reference. (b) All standard diffraction patterns of IrRu intermetallics extracted from ICDD.

As shown in Fig. S2b, there are ten standard diffraction patterns of IrRu intermetallics with different crystal structures, among which the patterns of cubic $\mathrm{Ru}_{0.37} \mathrm{Ir}_{\mathrm{o} .63}, \mathrm{Ir}_{\mathrm{o} .62} \mathrm{Ru}_{0.38}, \mathrm{Ru}_{0.4} \mathrm{Ir}_{\mathrm{o} .6}$, and $\mathrm{Ir}_{\mathrm{o} .6} \mathrm{Ru}_{\mathrm{o.4}}$ are similar to the experimentally measured pattern of IrRu@Te. Considering that the atomic ratio of $\operatorname{Ir}_{0.6} \mathrm{Ru}_{\mathrm{o.4}}$ is closer to our ICP results (Fig. S7, 1.34 in IrRu@Te and 1.28 in IrRu) than that of other intermetallics, IrRu in this work is assigned to $\mathrm{Ir}_{0.6} \mathrm{Ru}_{0.4}$. However, this only represents an average phase composition. Microscopically, the atomic ratio of Ir over Ru may vary from one grain/region to the other. 

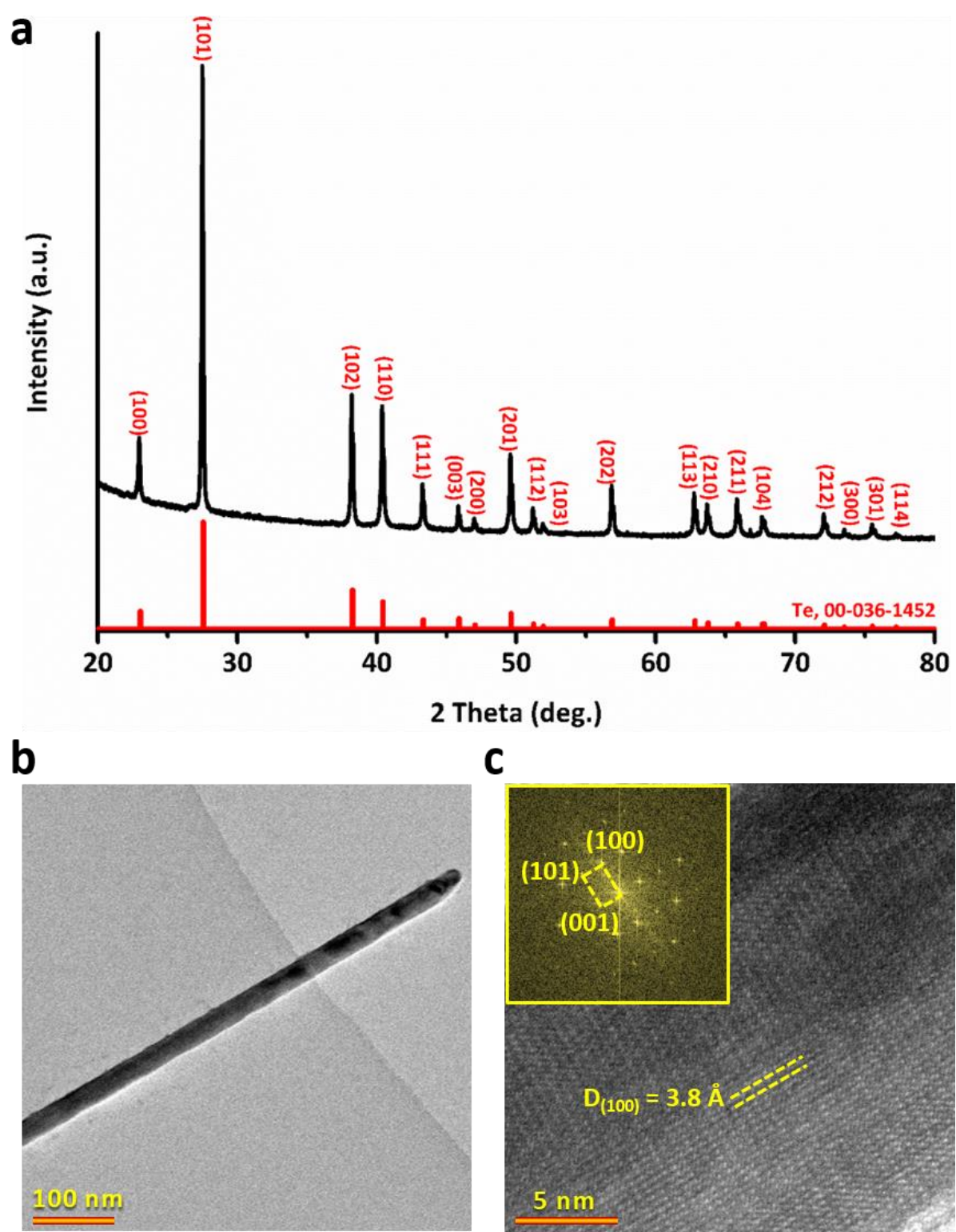

C

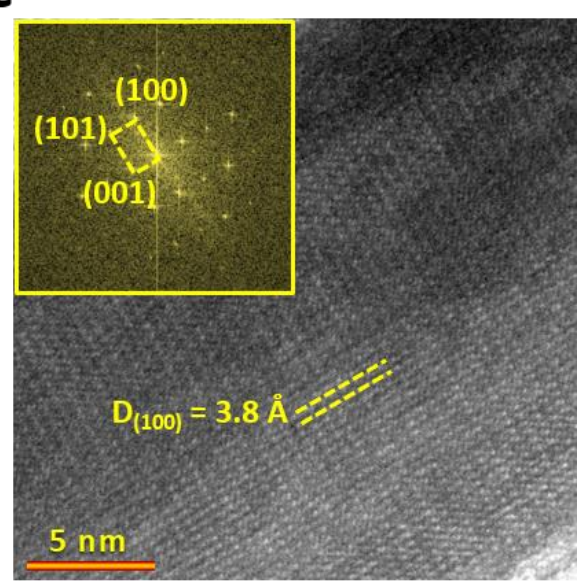

Figure S3. (a) XRD pattern of the pristine Te. The standard powder diffraction pattern of hexagonal Te (ICDD No. oo-036-1452) is given for reference. (b) TEM image. (c) HRTEM image, inset: the corresponding FFT-ED pattern. 


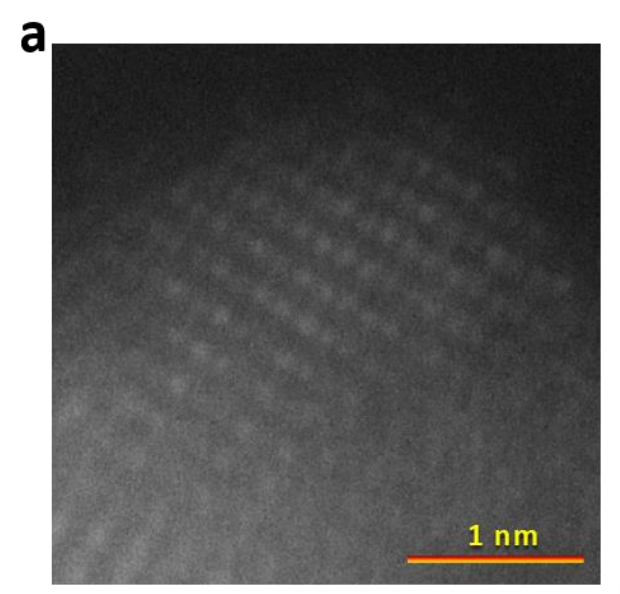

b

C

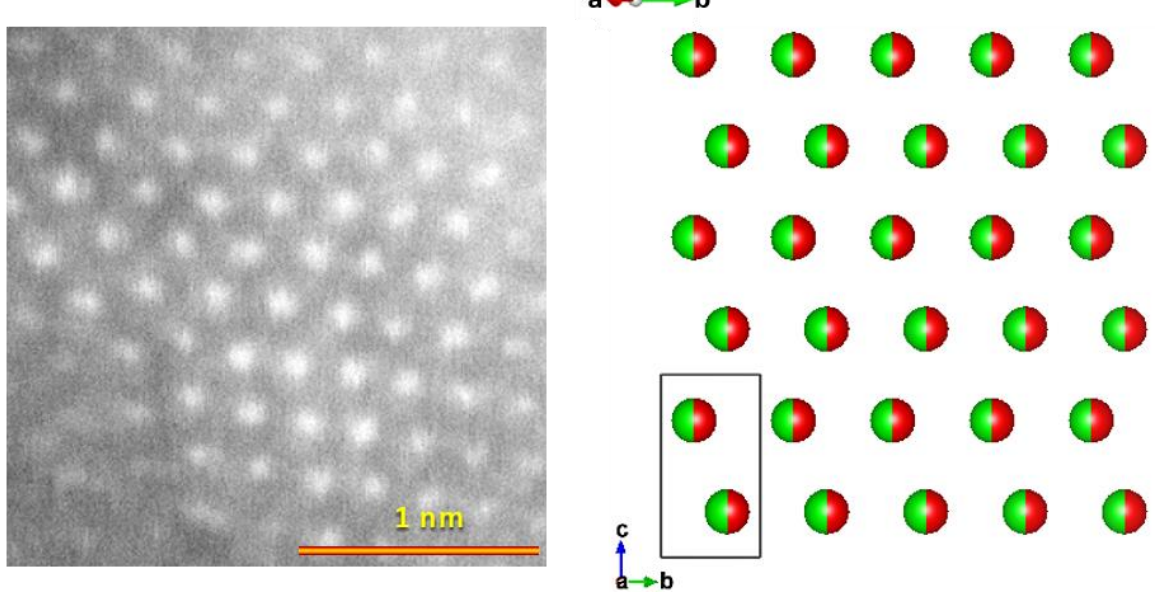

Figure S4. (a, c) Atomic resolution HAADF-STEM images of the as-obtained IrRu@Te catalysts. Schematic illustration of the atomic crystal structure of the hexagonal IrRu along (b) [210] and (d) [100] orientations. Red and green spheres represent Ir and Ru atoms, respectively. 

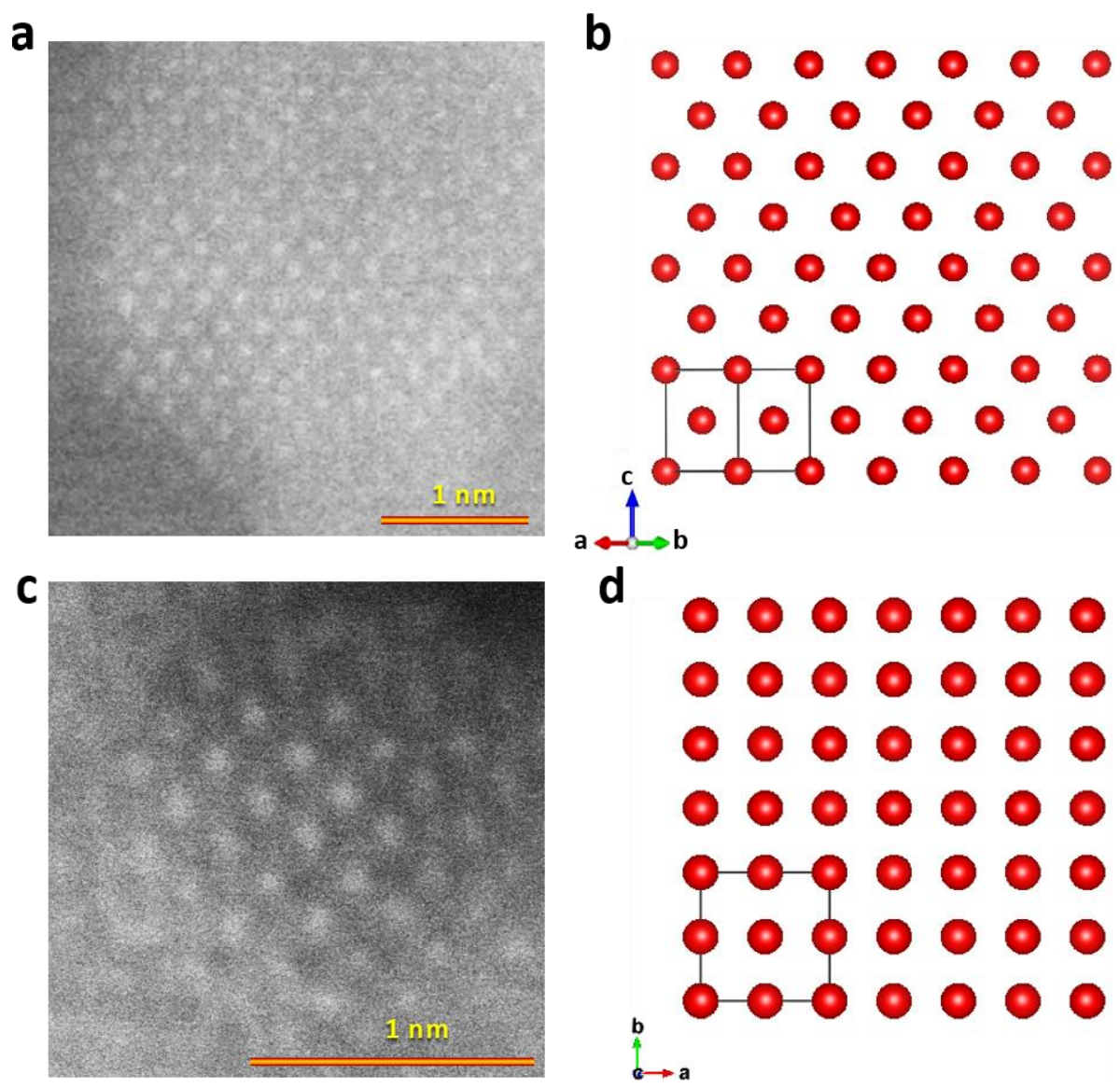

Figure S5. $_{5}$ (a, c) Atomic resolution HAADF-STEM images of the as-obtained IrRu@Te catalysts. Schematic illustration of the atomic crystal structure of fcc Ir (ICDD No. o1-071-3759) along the (b) [110] and (d) [oor] orientations. Red spheres represent Ir atoms. 

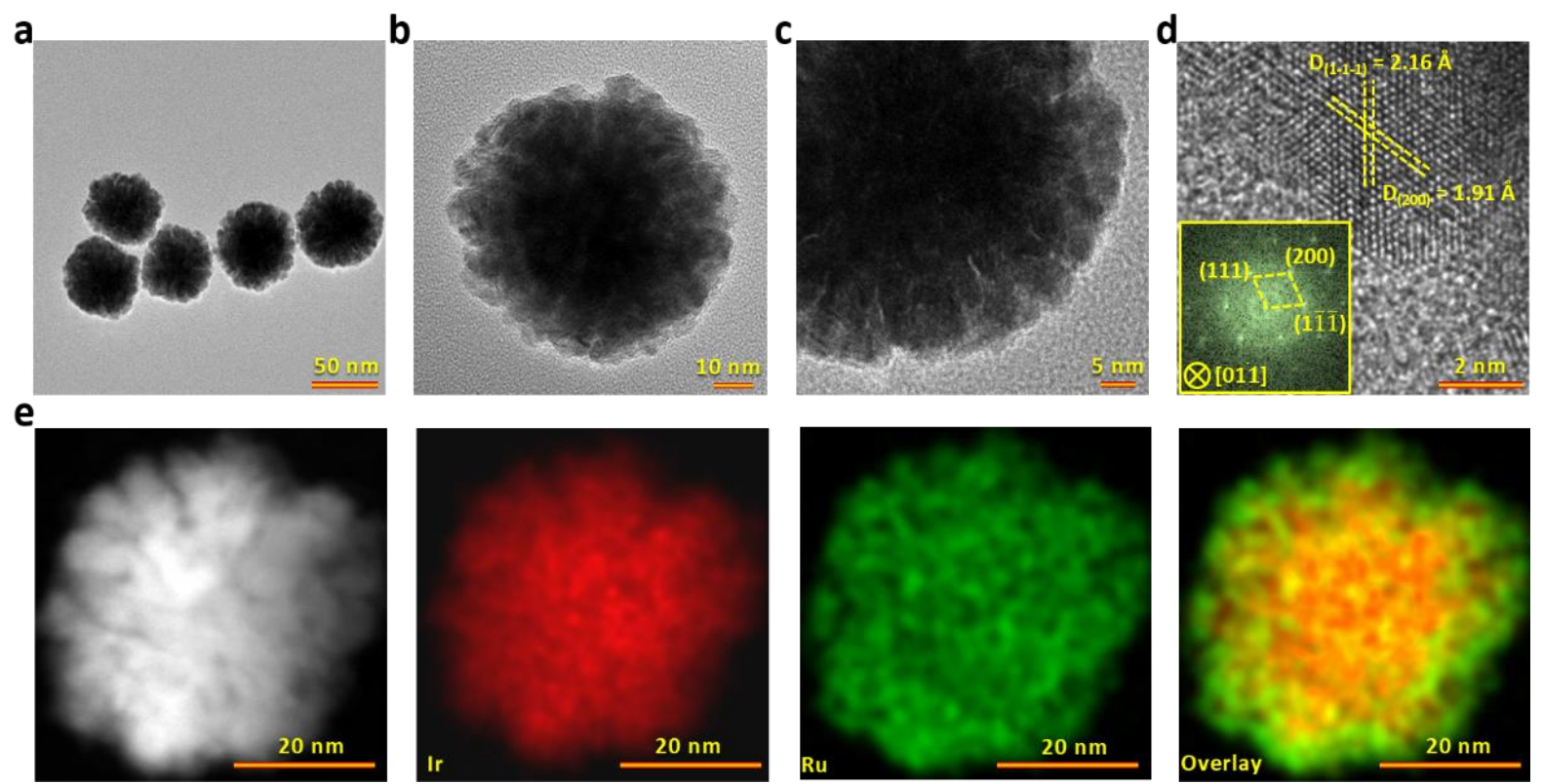

Figure S6. Morphology and microstructure of unsupported IrRu nanoparticles. (a-c) TEM images at different magnifications. (d) HRTEM image, inset: the corresponding FFT-ED pattern. (e) HAADF-STEM image and the elemental maps of Ir, Ru, and their overlay. 

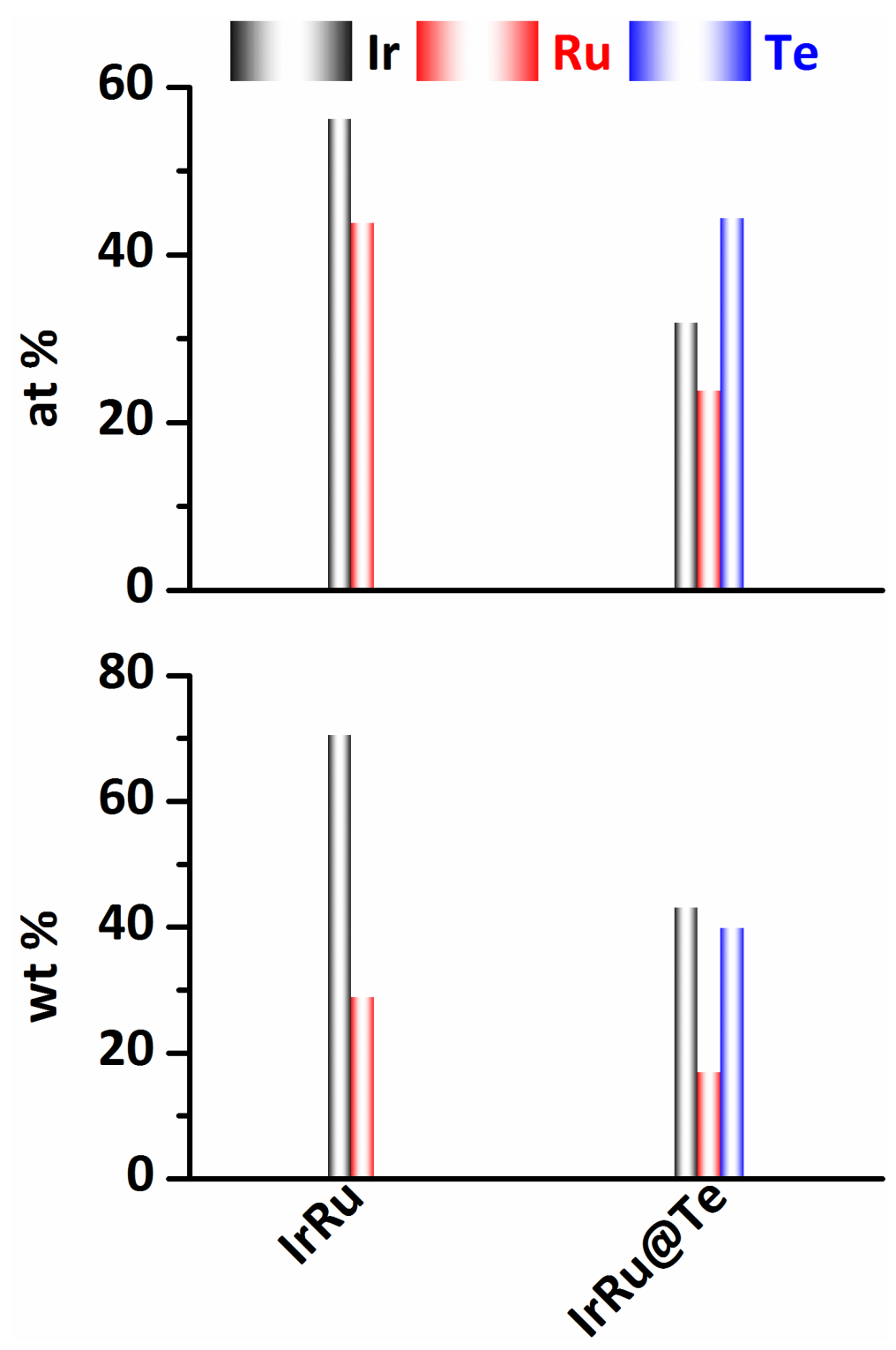

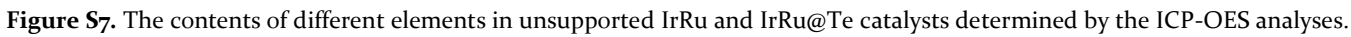




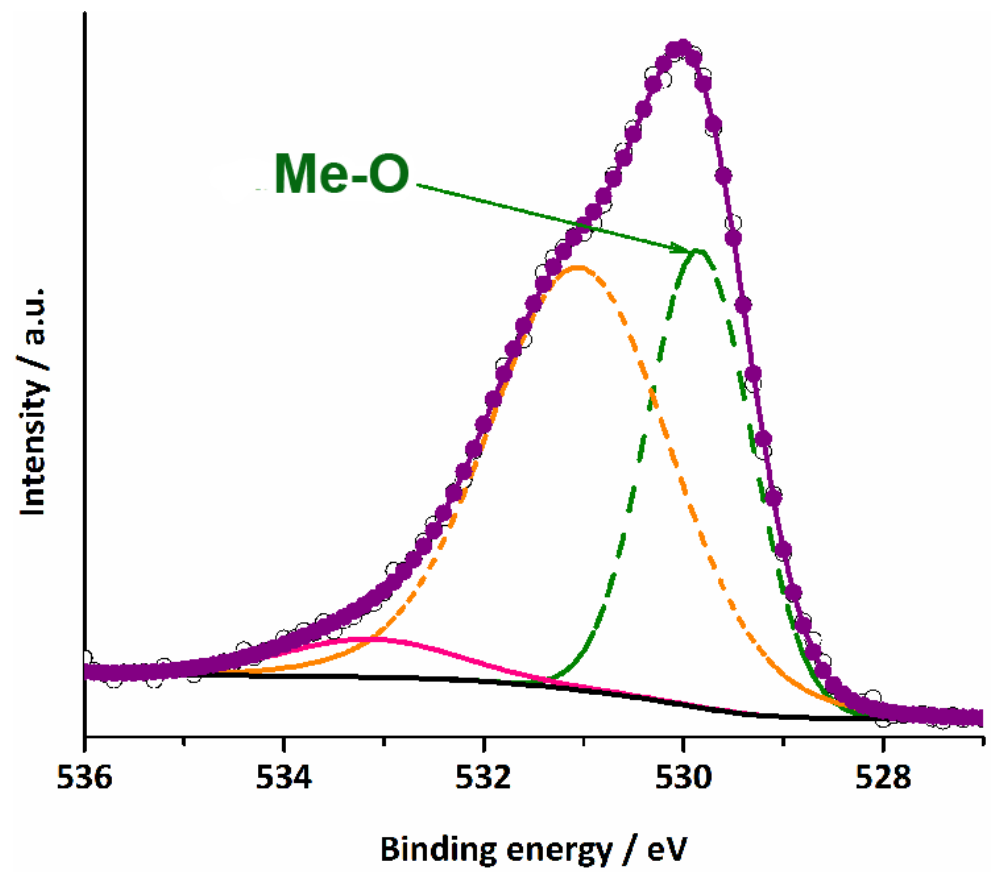

Figure S8. Os XPS spectra of the IrRu@Te catalyst. Scattered dots are experimentally measured data points, dotted lines are fitting curves of each component, and solid lines represent fitting curves of the overall spectra.

S12 


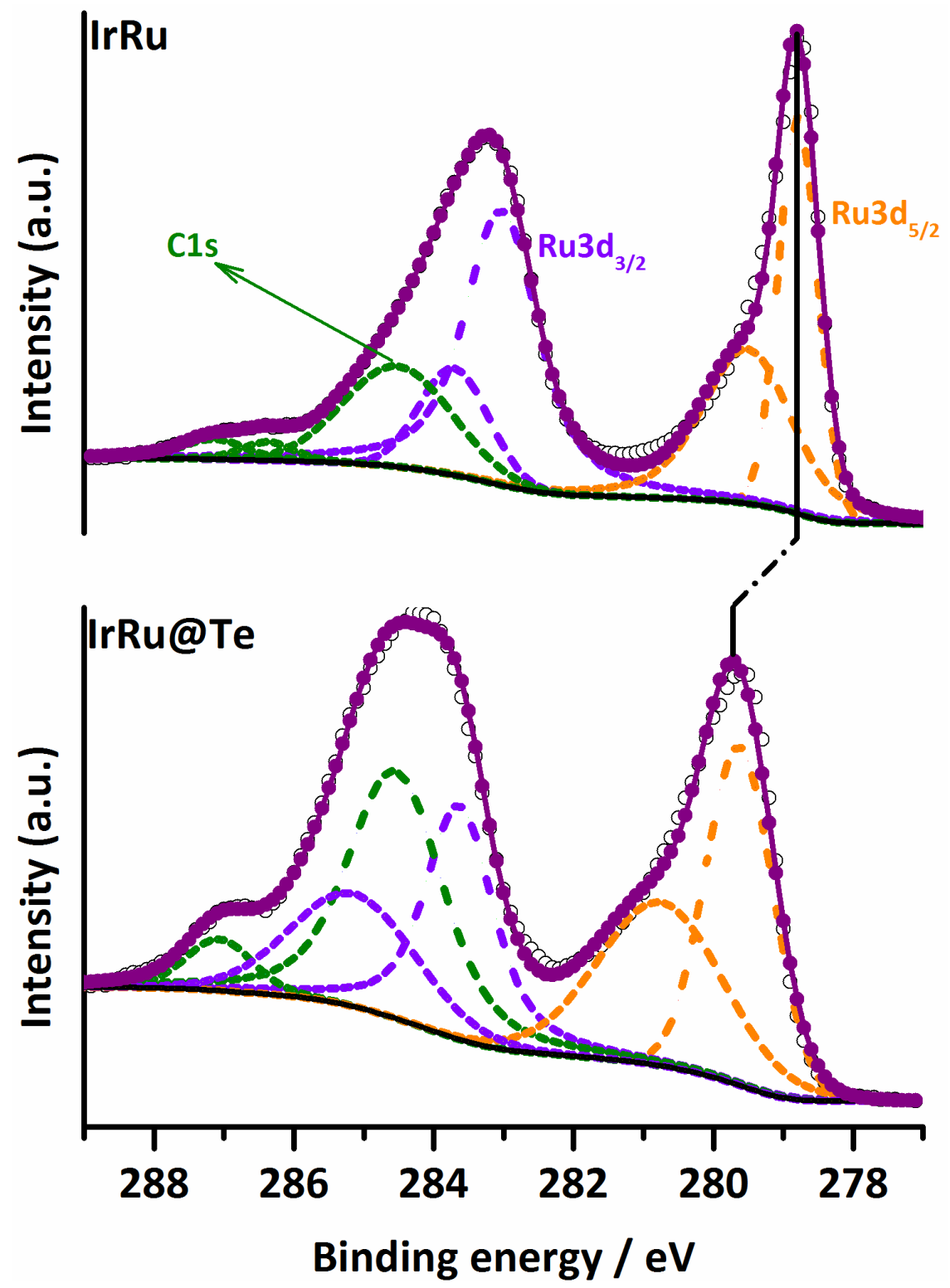

Figure S9. Ruzd-Cis XPS spectra of the IrRu@Te and unsupported IrRu catalysts. Scattered dots are experimentally measured data points, dotted lines are fitting curves of each component, and solid lines represent fitting curves of the overall spectra. 




Figure S1o. The optimized catalyst models for PDOS calculations. (a) unsupported IrRu, (b) IrRu@Te. The red, green and pink spheres represent Ir, $\mathrm{Ru}$, and Te atoms, respectively. 


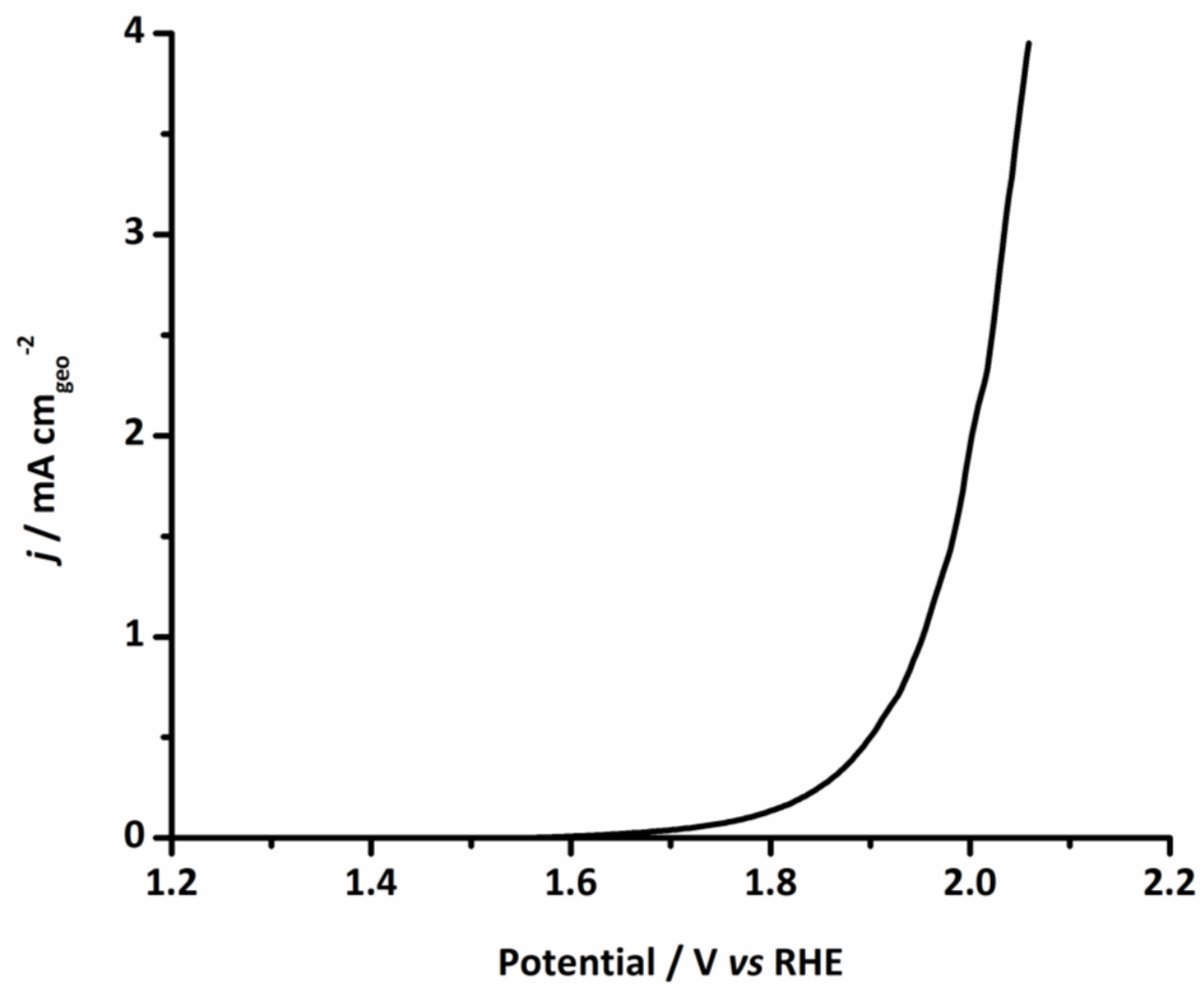

Figure S11. The $i R$-corrected CV curve of pristine Te NWs recorded at a scan rate of $5 \mathrm{mV} \mathrm{s}^{-1}$ in $0.5 \mathrm{M} \mathrm{H}_{2} \mathrm{SO}_{4}$ with a catalyst loading of 0.15 mg cm². 


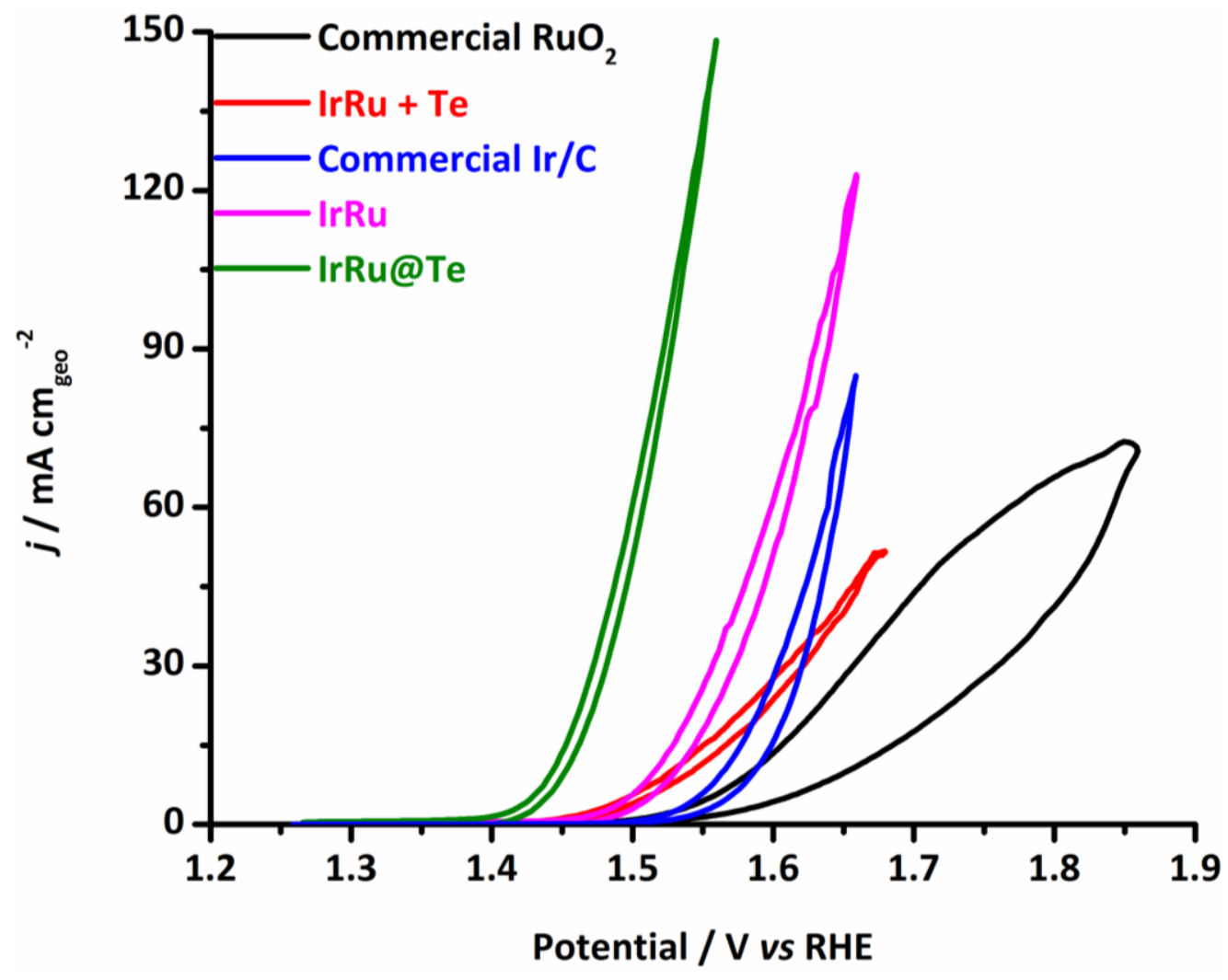

Figure S12. The $i R$-corrected CV curves of IrRu@Te and other control catalysts recorded at a scan rate of $5 \mathrm{mV} \mathrm{s}^{-1}$ in $0.5 \mathrm{M} \mathrm{H}_{2} \mathrm{SO}_{4}$ with a catalyst loading of $0.15 \mathrm{mg} \mathrm{cm}^{-2}$. 


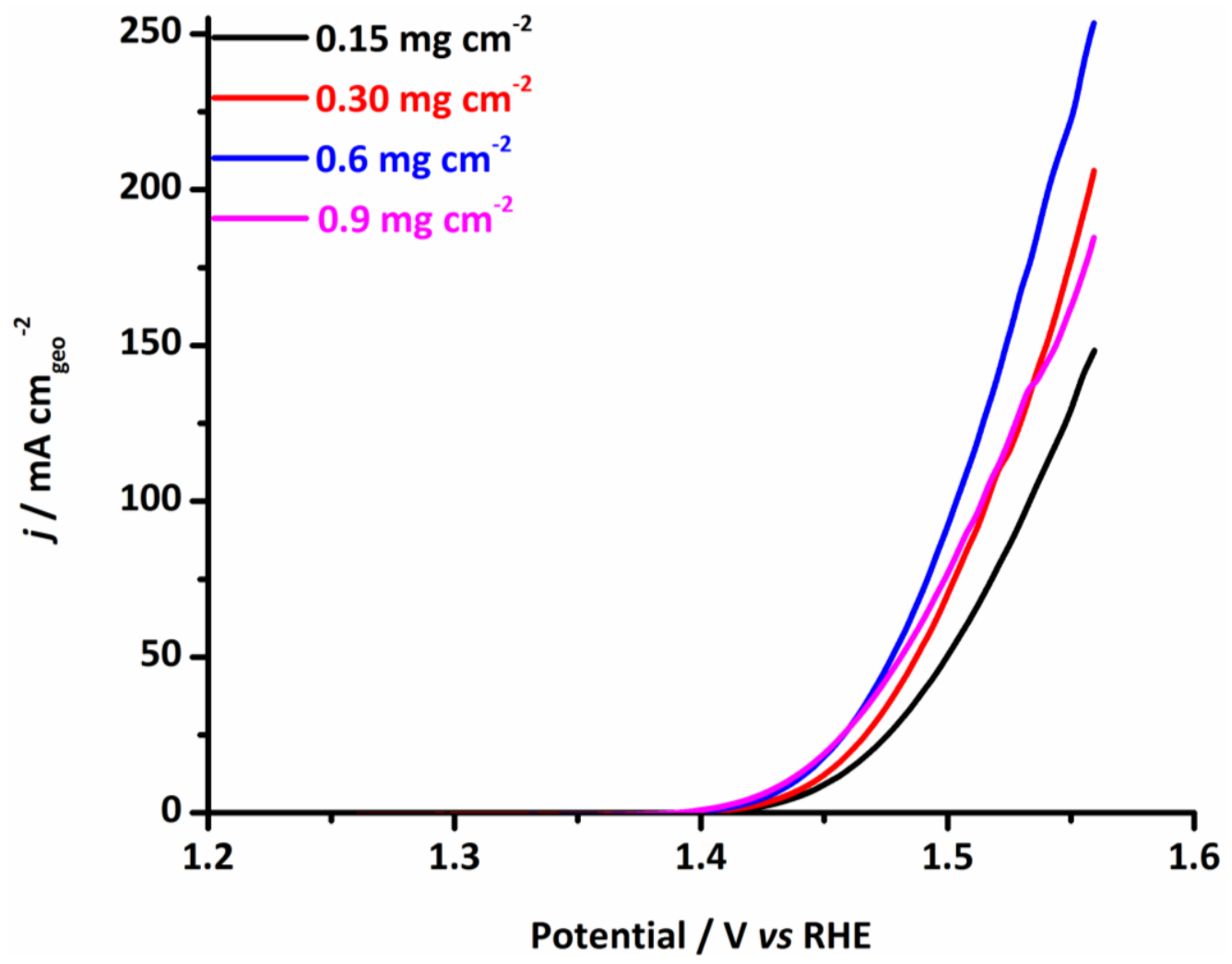

Figure S13. The $i R$-corrected polarization curves of IrRu@Te catalysts recorded at a scan rate of $5 \mathrm{mV} \mathrm{s}^{-1}$ in $0.5 \mathrm{M} \mathrm{H}_{2} \mathrm{SO}_{4}$ with different loading densities ranging from 0.15 to $0.90 \mathrm{mg} \mathrm{cm}^{-2}$ 


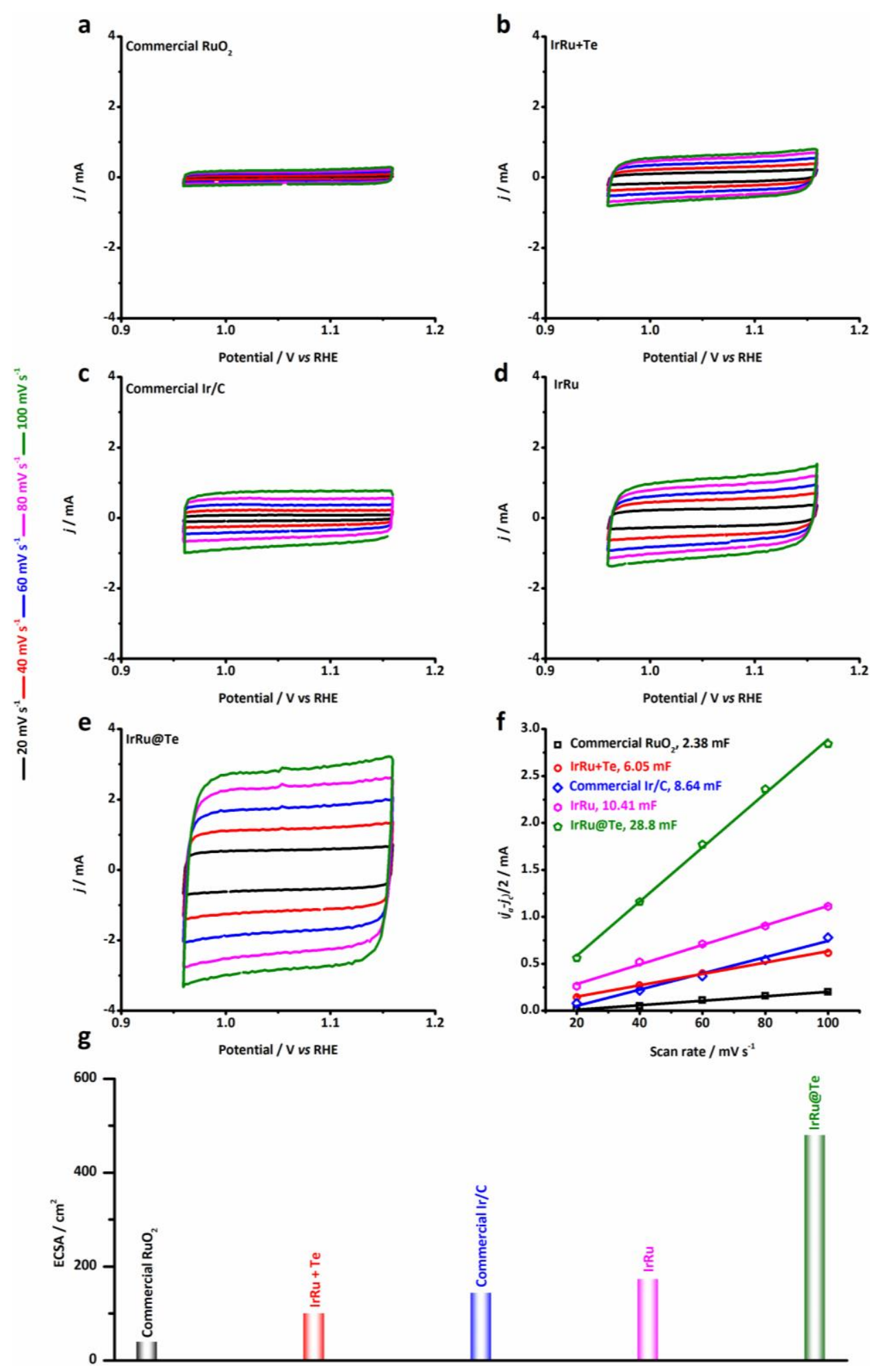

Figure S14. Electrochemical CV curves of (a) commercial $\mathrm{RuO}_{2}$, (b) physical mixture of unsupported IrRu and pristine Te NWs (IrRu + Te), (c) commercial Ir/C, (d) unsupported IrRu, and (e) IrRu@Te catalysts recorded at different scan rates of 20, 40, 60, 80 and $100 \mathrm{mV} \mathrm{s}$, with a loading density of $0.15 \mathrm{mg} \mathrm{cm}^{-2}$. (f) Plots of the capacitive currents as a function of the scan rate for all catalysts. (g) ECSAs of all catalysts. 


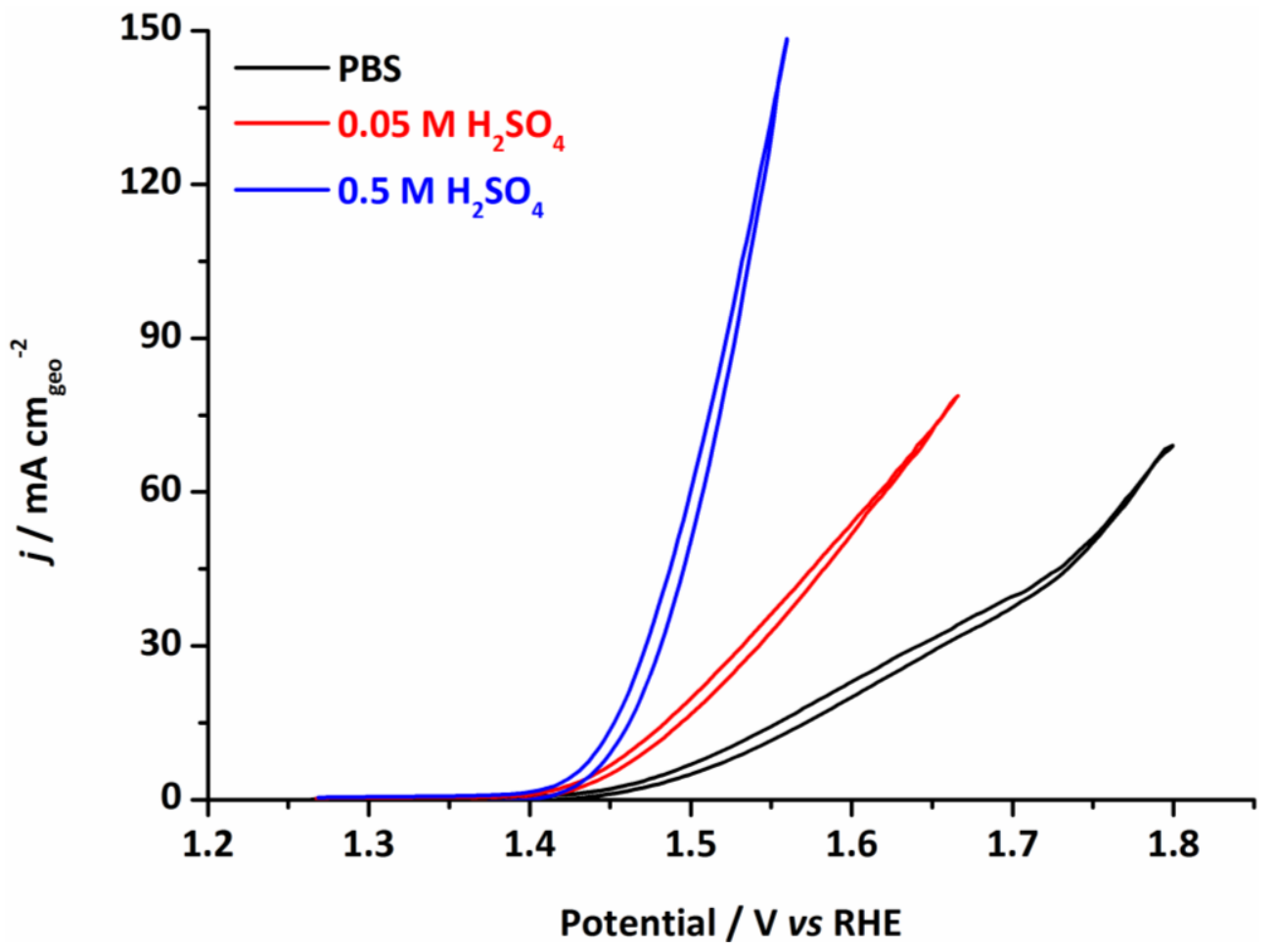

Figure S15. The $i R$-corrected CV curves of IrRu@Te measured in electrolytes of different $\mathrm{pH}$ values with a catalyst loading density of $0.15 \mathrm{mg} \mathrm{cm}^{-2}$. 


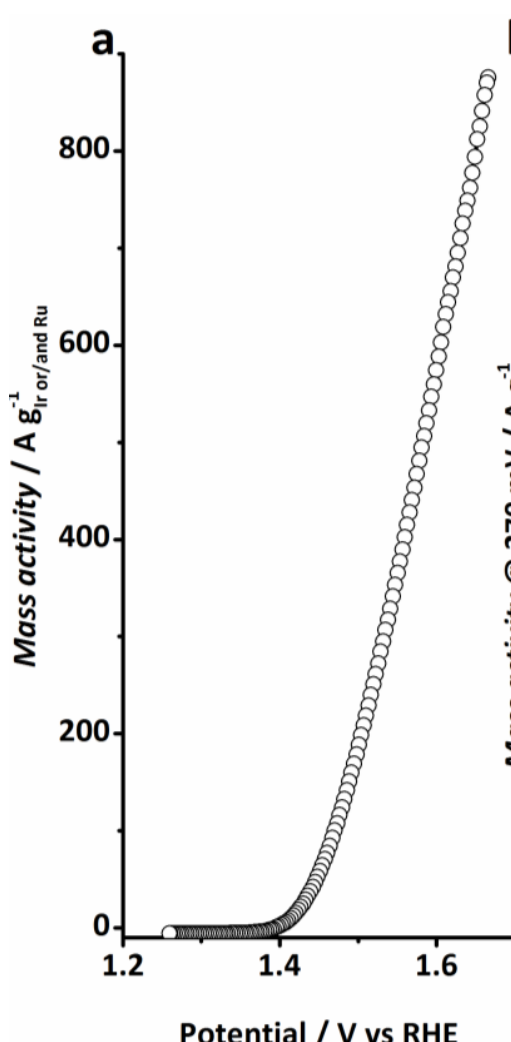

Ru@IrO, Chem, 2019, 5, 445

IrNi ${ }_{x}$ RDH/C, ACS Nano, 2018, 12, 7371

Cu-Ir Nanocage, J. Mater. Chem. A, 2015, 3, 19669 $\mathbf{b}_{300}$

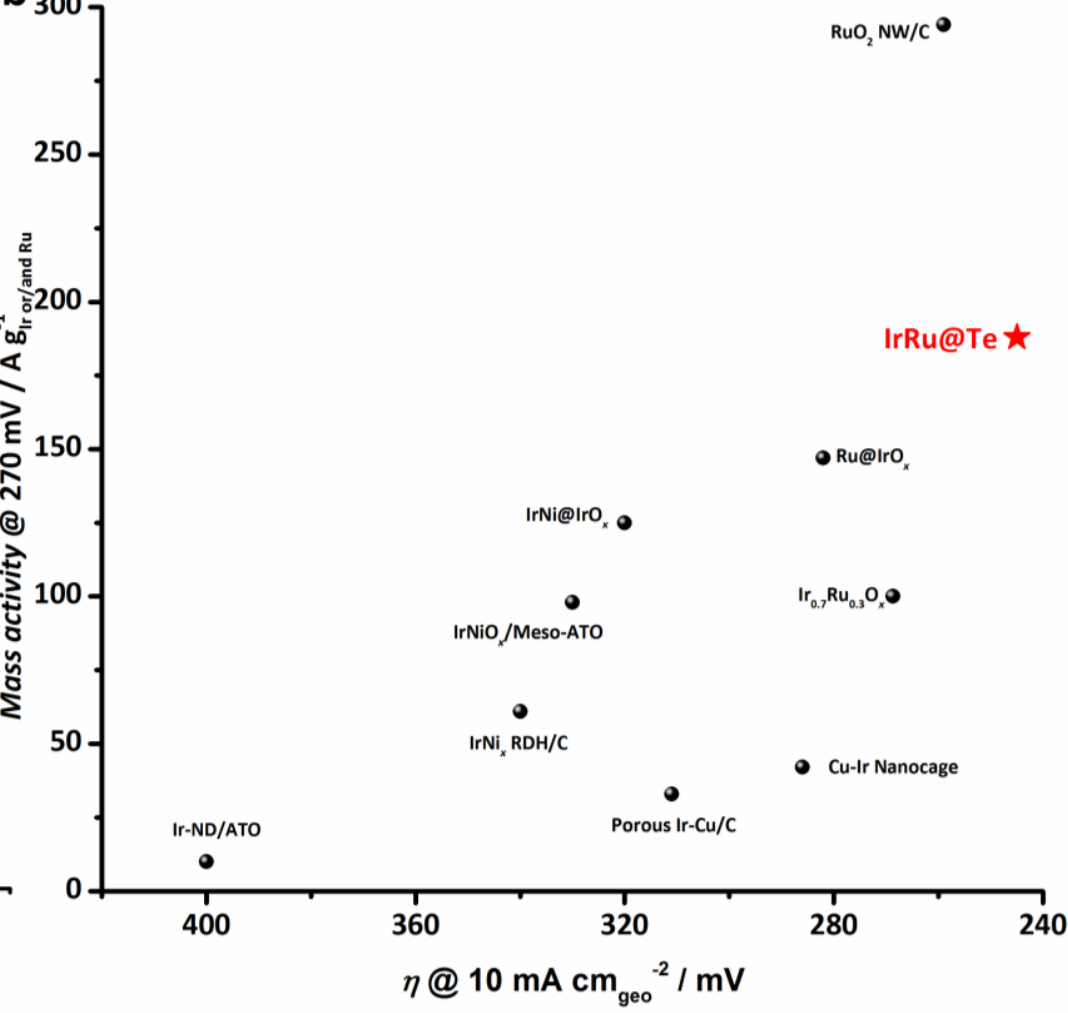

$\mathrm{RuO}_{2} \mathrm{NW} / \mathrm{C}$, Adv. Funct. Mater. 2018, 28, 1803722

$\mathrm{Ir}_{0.7} \mathrm{Ru}_{0.3} \mathrm{O}_{x^{\prime}}$ Nano Energy, 2017, 34, 385

Ir-ND/ATO, Chem. Sci., 2015, 6, 3321
Porous Ir-Cu/C, Chem. Mater. 2018, 30, 8571

IrNiO/Meso-ATO, Angew. Chem. Int. Ed. 2015, 54, 2975

IrNi@IrO, Chem. Sci., 2014, 5, 2955

Figure S16. (a) Mass activity of IrRu@Te catalysts in $0.05 \mathrm{M} \mathrm{H}_{2} \mathrm{SO}_{4}$. (b) Performance comparison of IrRu@Te catalysts with other advanced Ir- and Ru-based OER catalysts. The activity of all catalysts was measured in $0.05 \mathrm{M} \mathrm{H}_{2} \mathrm{SO}_{4}$. 

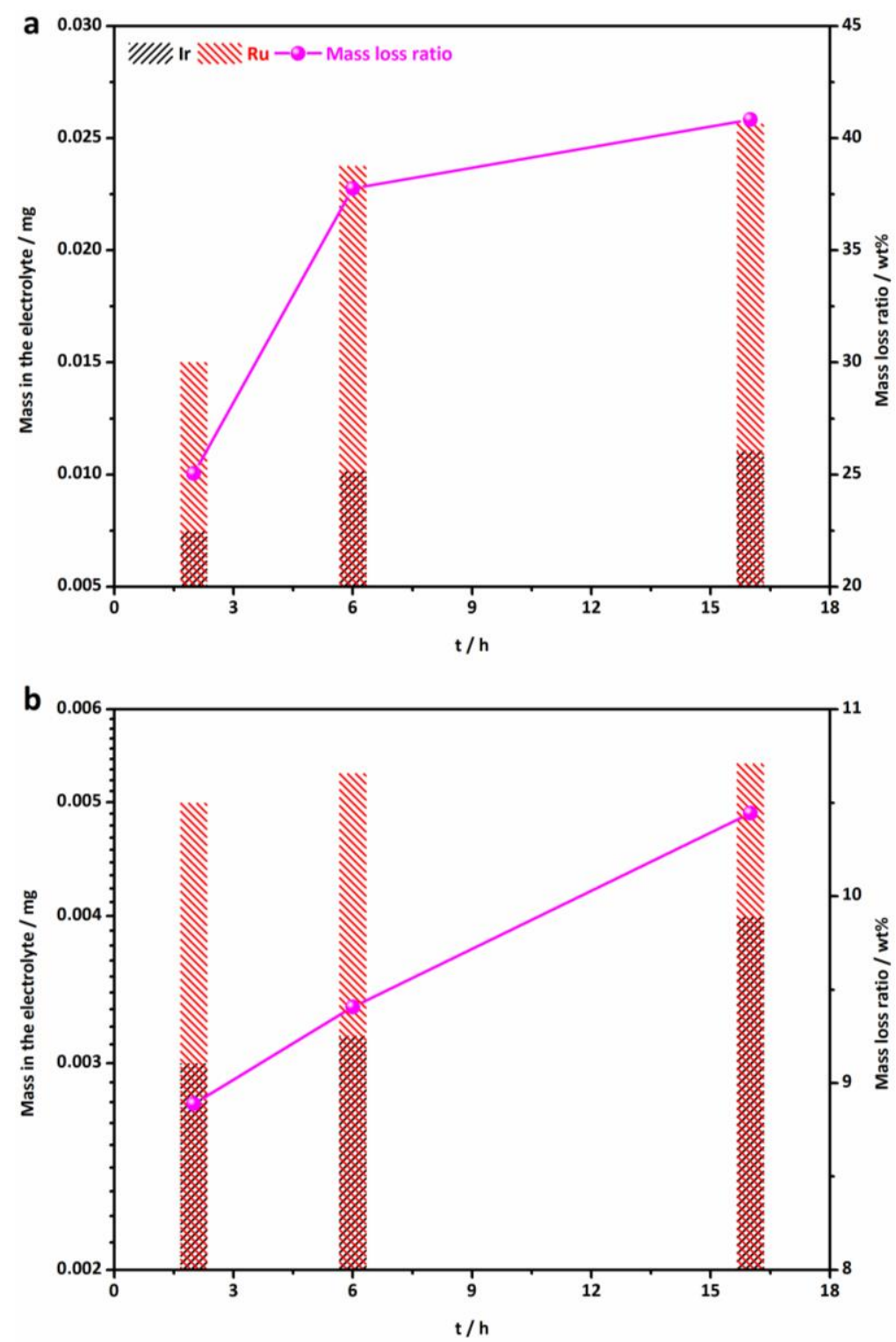

Figure S17. ICP analyses of the metal dissolution of (a) unsupported IrRu and (b) IrRu@Te catalysts after OER electrolysis at $10 \mathrm{~mA} \mathrm{~cm}^{-2}$ in $0.5 \mathrm{M}^{2}$ $\mathrm{H}_{2} \mathrm{SO}_{4}$ for different time intervals. 

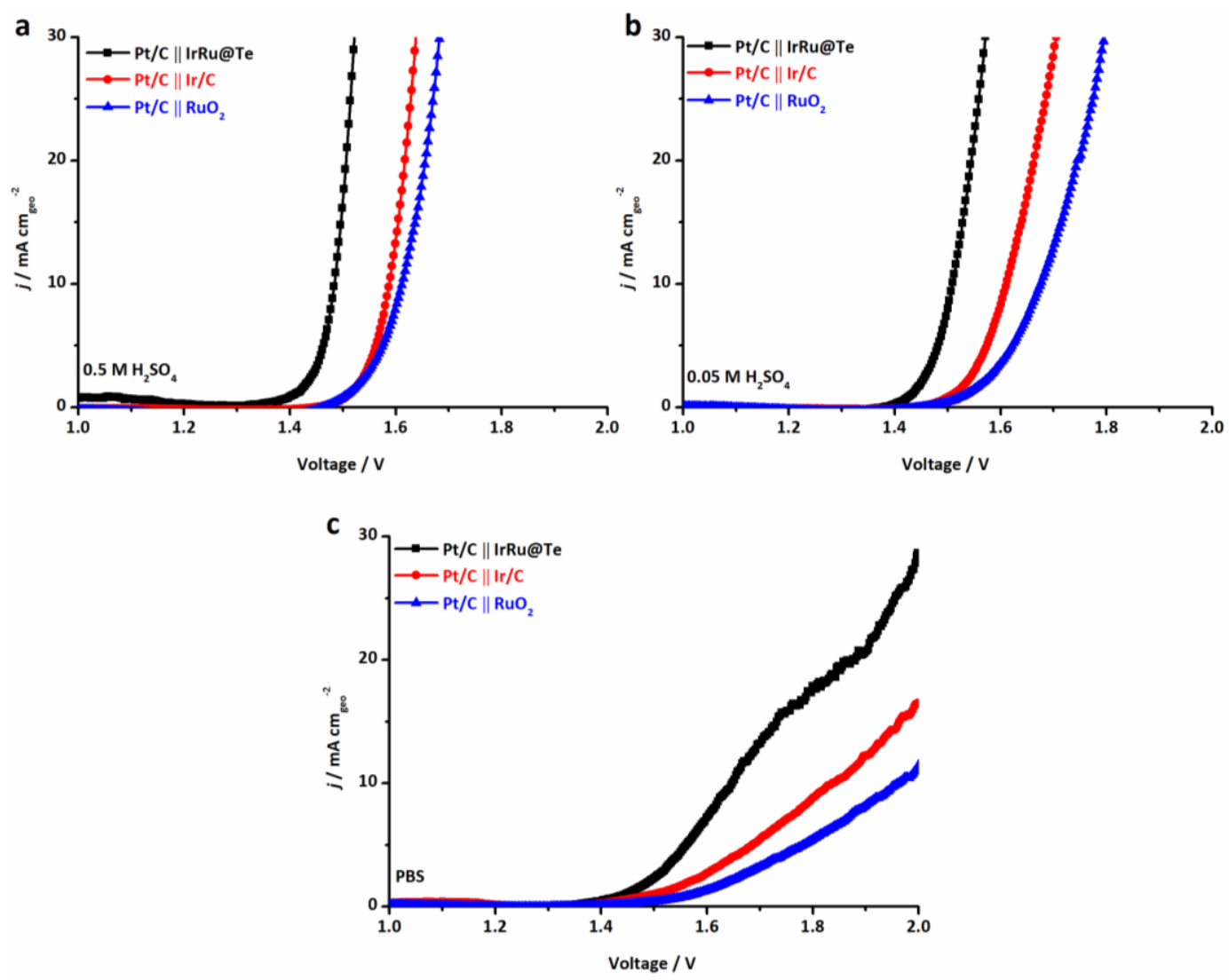

Figure S18. Polarization curves of the $\mathrm{Pt} / \mathrm{C}\|\mathrm{IrRu} @ \mathrm{Te}, \mathrm{Pt} / \mathrm{C}\| \mathrm{Ir} / \mathrm{C}$ and $\mathrm{Pt} / \mathrm{C} \| \mathrm{RuO}_{2}$ electrolyzers recorded in (a) o.5 $\mathrm{M} \mathrm{H}_{2} \mathrm{SO}_{4}$, (b) o.o5 $\mathrm{M} \mathrm{H}_{2} \mathrm{SO}_{4}$ and (c) PBS solution. The anode and cathode catalyst loading is $0.6 \mathrm{mg} \mathrm{cm}^{-2}$, and the anode and cathode were separated by a Nafion ${ }^{\circledast} 115 \mathrm{membrane}$ in a two-compartment testing cell. 

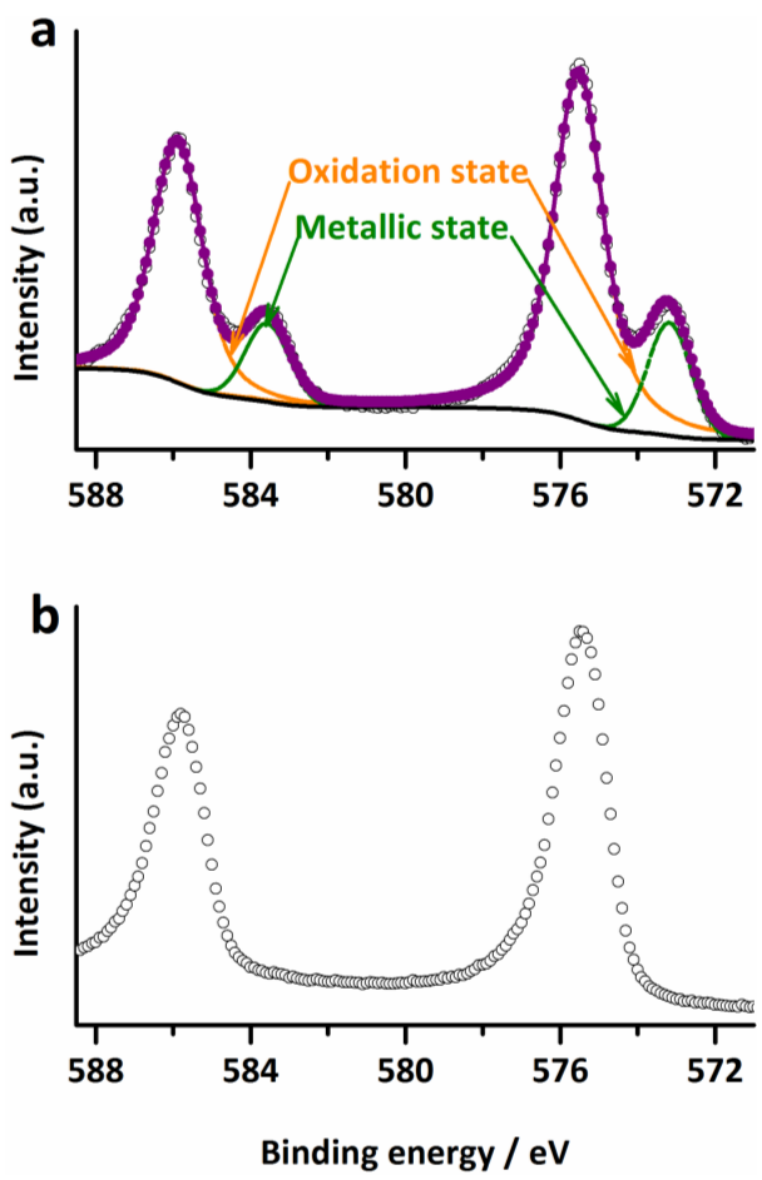

Figure S19. Tezd XPS spectra of (a) freshly prepared IrRu@Te and (b) IrRu@Te subjected to OER electrolysis at a constant current density of 1o mA $\mathrm{cm}^{-2}$ for $30 \mathrm{~min}$. Scattered dots are experimentally measured data points, dotted lines are fitting curves of each component, and solid lines represent fitting curves of the overall spectra. 

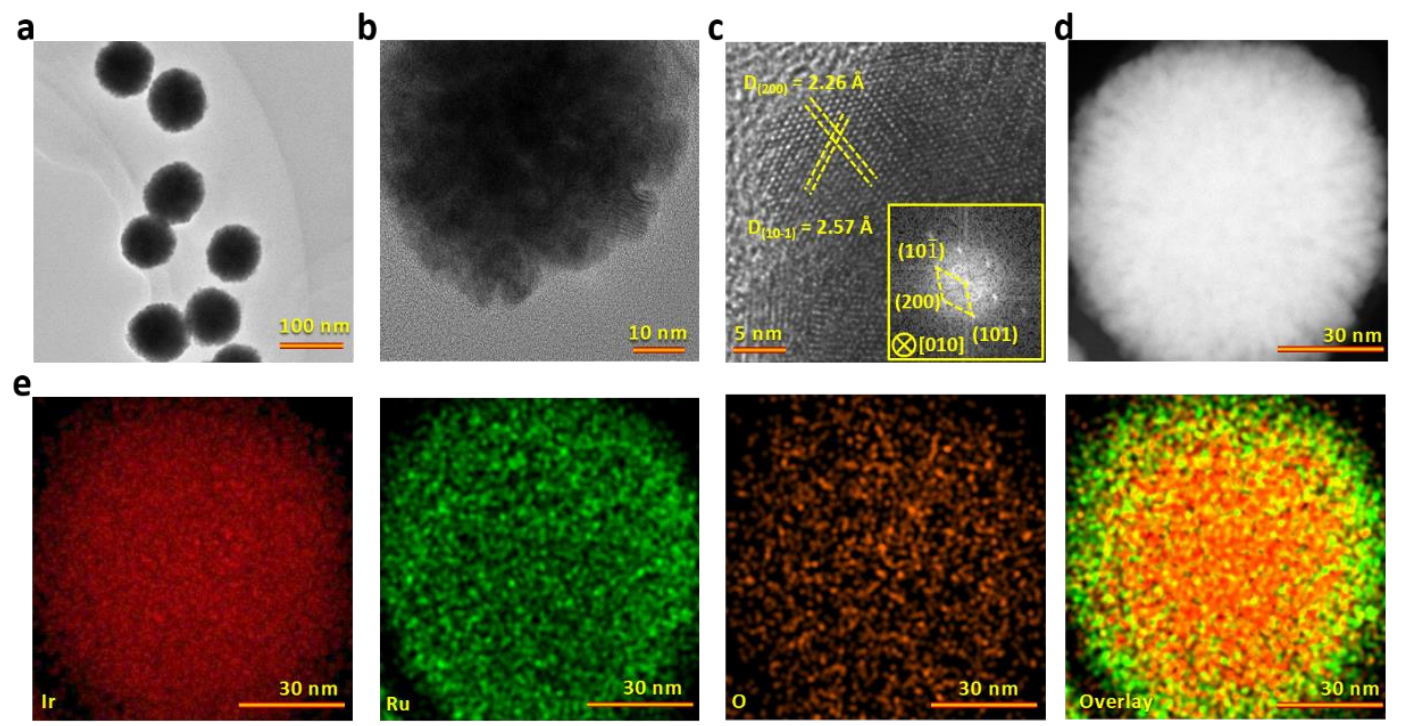

Figure S2o. Morphology and microstructure characterization of unsupported IrRu after OER electrolysis at a constant current density of $10 \mathrm{~mA} \mathrm{~cm}^{-2}$ for 30 min. (a-b) TEM images at different magnifications. (c) HRTEM image, inset: the corresponding FFT-ED pattern. (d-e) STEM-HAADF image and elemental maps of Ir, Ru, O and their overlay. 

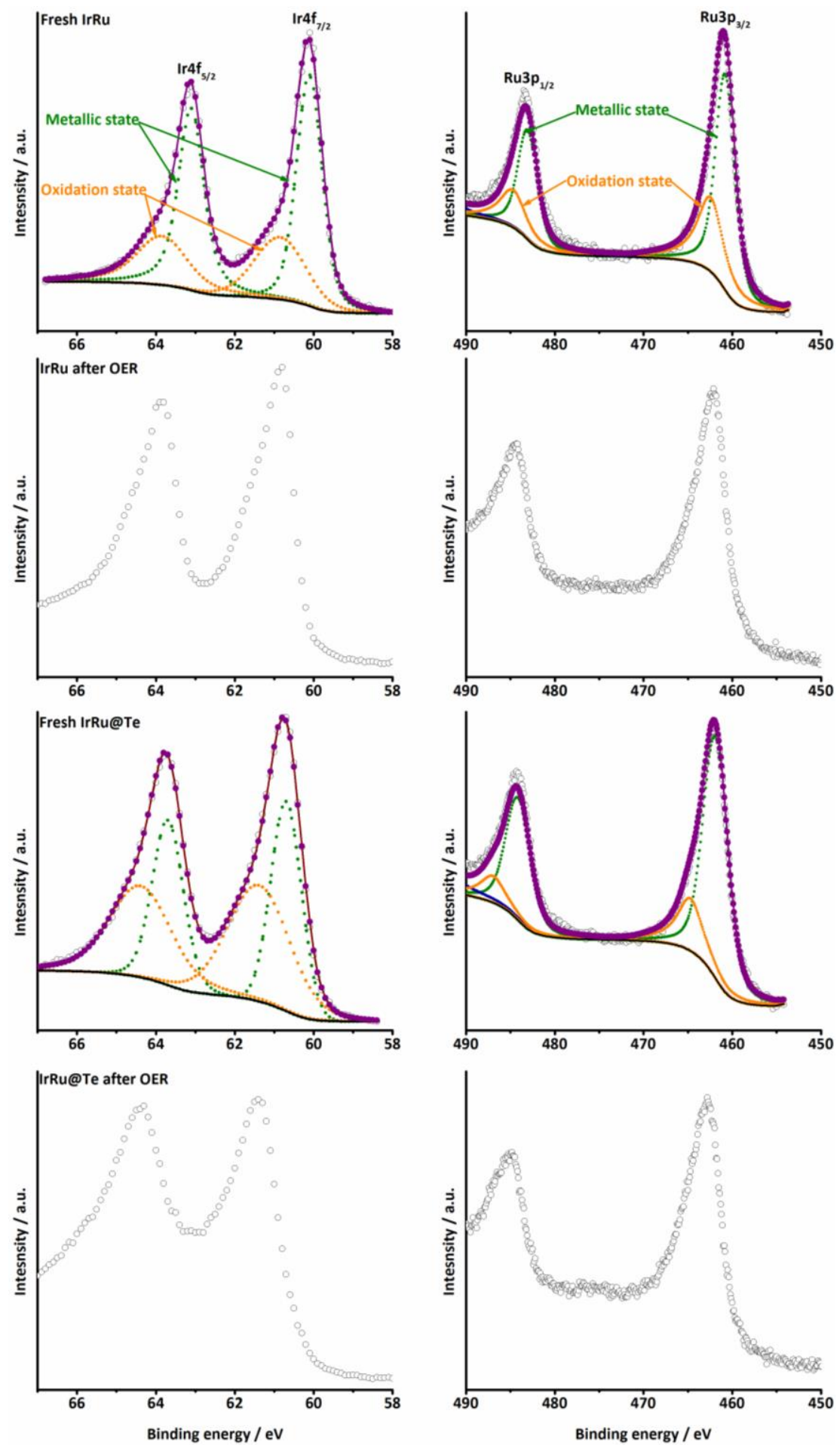

Figure S21. Ir af and Rump XPS spectra of unsupported IrRu and IrRu@Te before and after OER electrolysis at $10 \mathrm{~mA} \mathrm{~cm}^{-2}$ for $30 \mathrm{~min}$. Scattered dots are experimentally measured data points, dotted lines are fitting curves of each component, and solid lines represents fitting curves of the overall spectra.

S25 
a

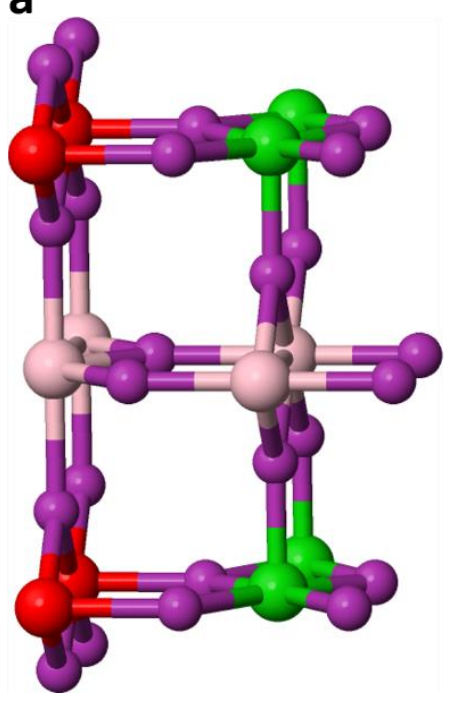

b

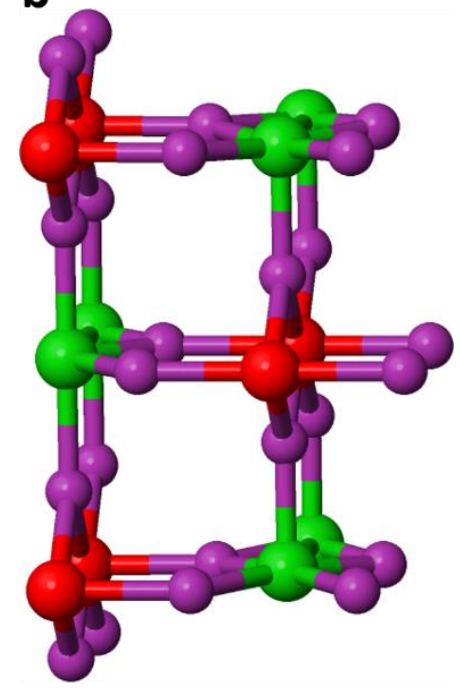

Figure S22. The optimized models of IrRu@Te and unsupported IrRu catalysts after oxidation. The red, green, pink and violet spheres represent Ir, $\mathrm{Ru}, \mathrm{Te}$ and $\mathrm{O}$ atoms, respectively. 
a

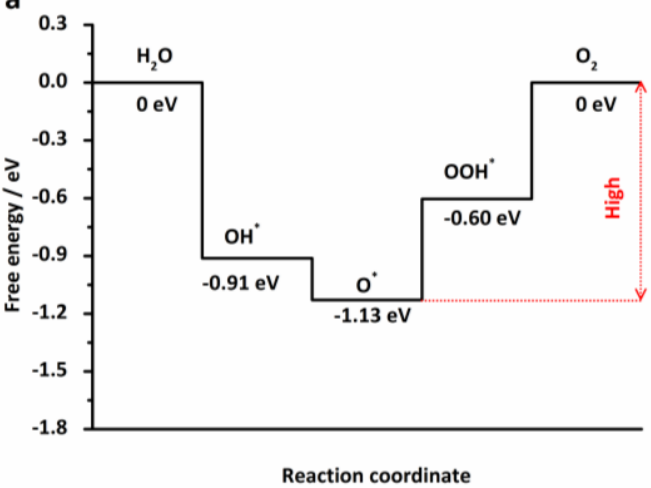

b

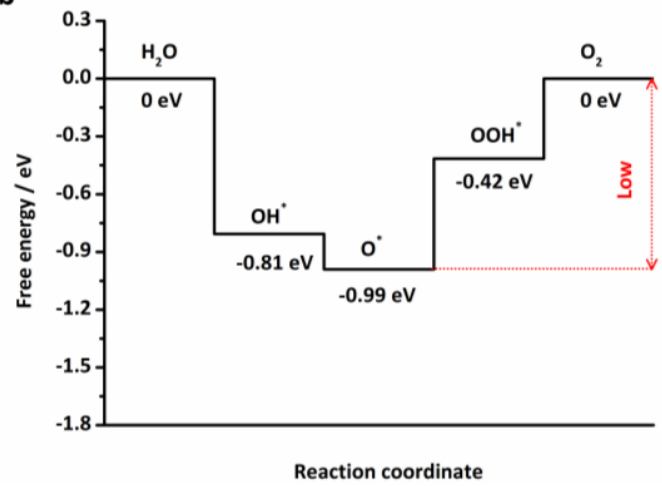

Figure S23. Gibbs free-energy diagram for the four steps of OER on (a) unsupported IrRu and (b) IrRu@Te after oxidation at U = 1.23 V. The optimized catalyst models from Fig. S22 were used for calculation. 


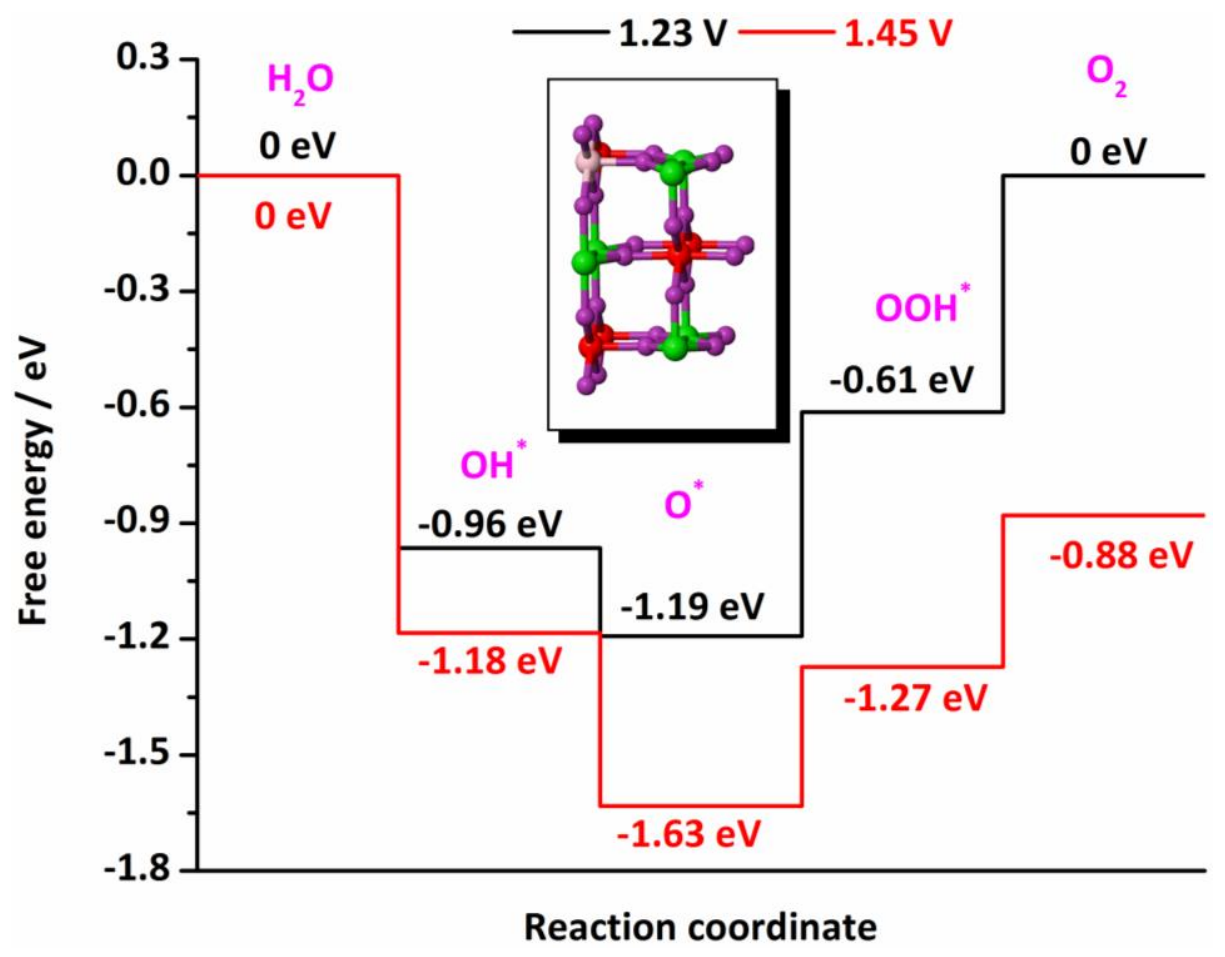

Figure S24. Gibbs free-energy diagram for the four steps of OER on IrRu@Te after oxidation with surface Ir atoms substituted by Te, calculated at U $=1.23$ and 1.45 V. The inset is the optimized catalyst model. The red, green, pink and violet spheres represent Ir, Ru, Te, and O atoms, respectively. 


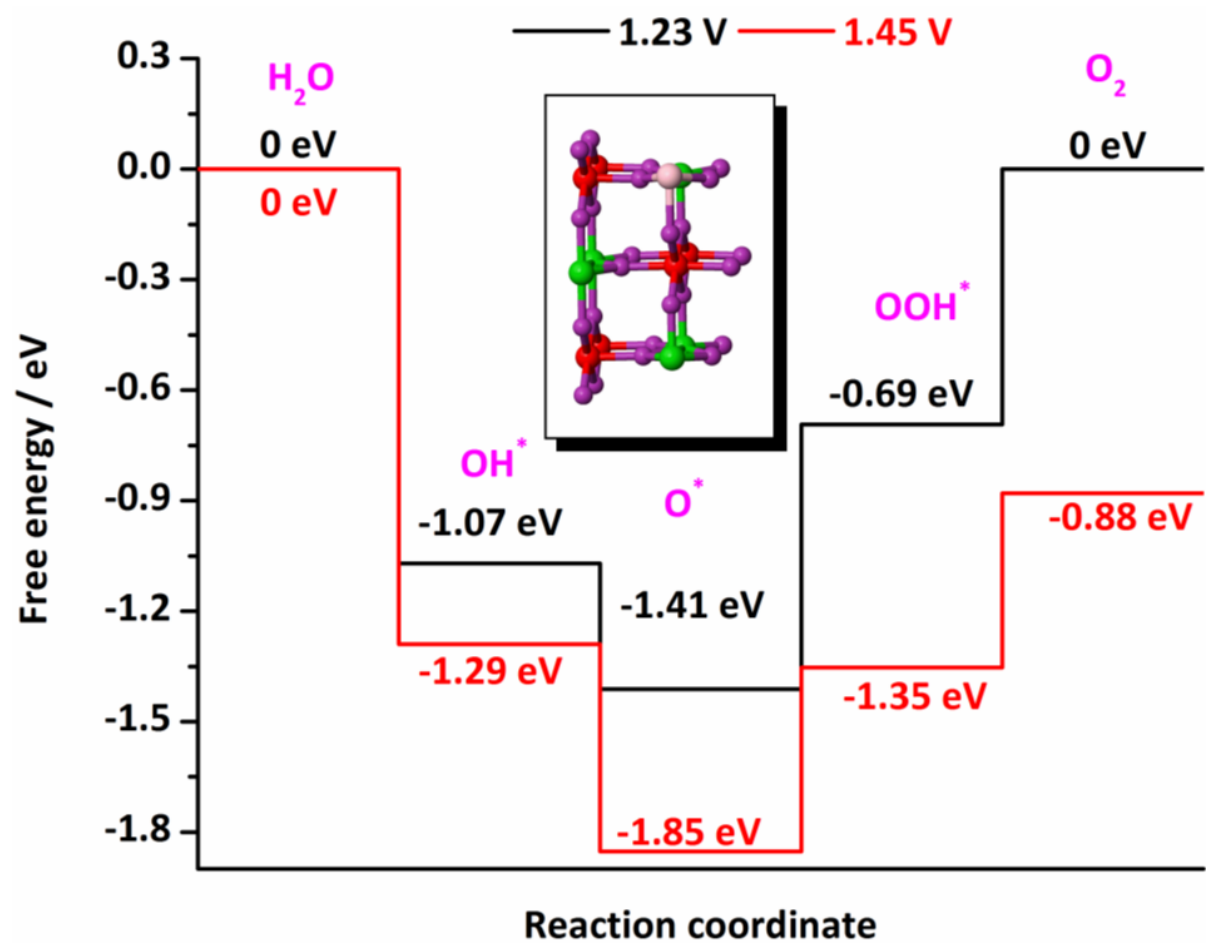

Figure S25. Gibbs free-energy diagram for the four steps of OER on IrRu@Te after oxidation with surface Ru atoms substituted by Te, calculated at $\mathrm{U}=1.23$ and $1.45 \mathrm{~V}$. The inset is the optimized catalyst model. The red, green, pink and violet spheres represent Ir, Ru, Te, and $\mathrm{O}$ atoms, respectively. 


\section{References}

(sı) Li, H. H.; Ma, S. Y.; Fu, Q. Q.; Liu, X. J.; Wu, L.; Yu, S. H. Scalable Bromide-Triggered Synthesis of Pd@Pt Core-Shell Ultrathin Nanowires with Enhanced Electrocatalytic Performance toward Oxygen Reduction Reaction. J. Am. Chem. Soc. 2015, 137, 78627868.

(s2) Kresse, G.; Hafner, J. Abinitio Molecular-Dynamics for Liquid-Metals. Phys. Rev. B 1993, 47, 558-561.

(s3) Kresse, G.; Furthmuller, J. Efficiency of Ab-Initio Total Energy Calculations for Metals and Semiconductors Using a PlaneWave Basis Set. Comput. Mater. Sci. 1996, 6, 15-50.

(s4) Kresse, G.; Furthmuller, J. Efficient Iterative Schemes for Ab Initio Total-Energy Calculations Using a Plane-Wave Basis Set. Phys. Rev. B 1996, 54, 11169-11186.

(s5) Blochl, P. E. Projector Augmented-Wave Method. Phys. Rev. B 1994, 50, 17953-17979.

(s6) Kresse, G.; Joubert, D. From Ultrasoft Pseudopotentials to the Projector Augmented-Wave Method. Phys. Rev. B 1999, 59, 1758-1775.

(s7) Hammer, B.; Hansen, L. B.; Nørskov, J. K. Improved Adsorption Energetics within Density-Functional Theory Using Revised Perdew-Burke-Ernzerhof Functionals. Phys. Rev. B 1999, 59, 7413-7421.

(s8) Grimme, S.; Antony, J.; Ehrlich, S.; Krieg, H. A Consistent and Accurate Ab Initio Parametrization of Density Functional Dispersion Correction (Dft-D) for the 94 Elements H-Pu. J. Chem. Phys. 2010, 132, 154104.

(s9) Seitz, L. C.; Dickens, C. F.; Nishio, K.; Hikita, Y.; Montoya, J.; Doyle, A.; Kirk, C.; Vojvodic, A.; Hwang, H. Y.; Norskov, J. K.; Jaramillo, T. F. A highly active and stable $\mathrm{IrO}_{x} / \mathrm{SrIrO}_{3}$ catalyst for the oxygen evolution reaction. Science 2o16, 353, $1011-1014$.

(s10) Nørskov, J. K.; Rossmeisl, J.; Logadottir, A.; Lindqvist, L.; Kitchin, J. R.; Bligaard, T.; Jónsson, H. Origin of the Overpotential for Oxygen Reduction at a Fuel-Cell Cathode. J. Phys. Chem. B 2004, 108, 17886-17892.

(s11) Shan, J. Q.; Guo, C. X.; Zhu, Y. H.; Chen, S. M.; Song, L.; Jaroniec, M.; Zheng, Y.; Qiao, S. Z. Charge-Redistribution-Enhanced Nanocrystalline Ru@IrO ${ }_{x}$ Electrocatalysts for Oxygen Evolution in Acidic Media. Chem 2019, 5, 445-459. 